\title{
Track Uncertainty in High-Resolution HWRF Ensemble Forecasts of Hurricane Joaquin
}

\author{
GHASSAN J. AlAKA JR. ${ }^{a}$ AND XUEJIN ZHANG ${ }^{\text {a }}$ \\ Cooperative Institute for Marine and Atmospheric Studies, University of Miami, and NOAA/AOML/Hurricane \\ Research Division, Miami, Florida \\ SUNDARARAMAN G. GOPALAKRISHNAN \\ NOAA/AOML/Hurricane Research Division, Miami, Florida \\ ZHAN ZHANG \\ NOAA/NCEP/Environmental Modeling Center, College Park, Maryland \\ FRANK D. MARKS \\ NOAA/AOML/Hurricane Research Division, Miami, Florida \\ ROBERT ATLAS \\ NOAA/Atlantic Oceanographic and Meteorological Laboratory, Miami, Florida
}

(Manuscript received 12 February 2019, in final form 26 August 2019)

\begin{abstract}
Hurricane Joaquin (2015) was characterized by high track forecast uncertainty when it approached the Bahamas from 29 September 2015 to 1 October 2015, with 5-day track predictions ranging from landfall in the United States to east of Bermuda. The source of large track spread in Joaquin forecasts is investigated using an ensemble prediction system (EPS) based on the Hurricane Weather Research and Forecasting (HWRF) Model. For the first time, a high-resolution analysis of an HWRF-based EPS is performed to isolate the factors that control tropical cyclone (TC) track uncertainty. Differences in the synoptic-scale environment, the TC vortex structure, and the TC location are evaluated to understand the source of track forecast uncertainty associated with Joaquin, especially at later lead times when U.S. landfall was possible. EPS members that correctly propagated Joaquin into the central North Atlantic are compared with members that incorrectly predicted U.S. landfall. Joaquin track forecasts were highly dependent on the evolution of the environment, including weak atmospheric steering flow near the Bahamas and three synoptic-scale systems: a trough over North America, a ridge to the northeast of Joaquin, and an upper-tropospheric trough to the east of Joaquin. Differences in the steering flow were associated with perturbations of the synoptic-scale environment at the model initialization time. Ultimately, members that produced a more progressive midlatitude synoptic-scale pattern had reduced track errors. Joaquin track forecast uncertainty was not sensitive to the TC vortex structure or the initial TC position.
\end{abstract}

\section{Introduction}

Hurricane Joaquin was the strongest tropical cyclone (TC) of the 2015 North Atlantic hurricane season (Berg

\footnotetext{
${ }^{a}$ Current affiliation: NOAA/AOML/Hurricane Research Division, Miami, Florida.
}

Corresponding author: Ghassan J. Alaka Jr., ghassan.alaka@ noaa.gov
2016). Joaquin developed from a nontropical mid- to upper-tropospheric low pressure system in the western North Atlantic Ocean and rapidly intensified in an environment of moderate north-northwesterly deep vertical wind shear as it meandered near the Bahamas (Berg 2016). Hurricane Joaquin reached category 4 on the Saffir-Simpson hurricane wind scale (Simpson and Saffir 1974) and was the strongest TC of nontropical origin in the last three decades (Berg 2016). Joaquin devastated the Bahamas with extreme wind and storm 
surge for several days and took the lives of 33 crewmembers when it sank the U.S. cargo ship El Faro (Berg 2016; National Transportation Safety Board 2017). Fortunately, Joaquin turned sharply to the northeast and dissipated in the central North Atlantic Ocean without directly impacting the U.S. mainland.

As Joaquin meandered near the Bahamas, an already dangerous situation was further complicated when operational forecasts indicated the potential for extreme impacts in major population centers along the U.S. East Coast. In fact, several numerical weather prediction models forecasted Joaquin to approach the United States as a major hurricane. The spread of track forecasts was quite large from 1200 UTC 29 September 2015 to 0000 UTC 1 October 2015 when Joaquin was drifting near the Bahamas, with 5-day position predictions ranging from inland over the United States to east of Bermuda. The high track uncertainty of Joaquin forecasts combined with the potential for U.S. landfall created a difficult scenario for forecasters at the National Centers for Environment Prediction (NCEP) National Hurricane Center (NHC) of the National Oceanic and Atmospheric Administration (NOAA) National Weather Service (NWS).

TC track forecasts are sensitive to the evolution of the environment and the TC vortex (e.g., depth, tilt, location). TC motion is generally governed by the surrounding synoptic-scale environment and can be modulated by vortex-environment interactions ( $\mathrm{Wu}$ and Kurihara 1996; Chan 2005). Small uncertainties in the environment can drastically alter TC track forecasts (Zhang and Krishnamurti 1999). The layer-mean wind field, known as "steering flow," describes how the synoptic-scale environment guides the propagation of a TC (Riehl and Shafer 1944; Miller 1958; Kasahara and Platzman 1963; George and Gray 1976; Brand et al. 1981; Chan and Gray 1982; Holland 1983; Carr and Elsberry 1990; Velden and Leslie 1991). Typically, TC tracks are more uncertain when the steering flow is weak or differs significantly with height (Majumdar and Finocchio 2010). For example, a col, the point of relatively lowest pressure between two highs and of relatively highest pressure between two lows, indicates a deformation zone associated with weak steering flow. Several studies have shown col development near a TC ahead of a progressing synoptic-scale trough, leading to high track uncertainty (Scheck et al. 2011; Grams et al. 2013; Riemer and Jones 2014). Hence, track forecast uncertainty tends to increase for a TC in proximity to a col, as was the case for Joaquin.

TC vortex structure determines how a TC interacts with its environment and has implications for TC motion. The depth of the TC vortex determines the atmospheric layer responsible for steering the TC (Velden and Leslie 1991), and a strong TC typically has a deeper vortex than a weak one (Stern and Nolan 2011). Except in purely barotropic fluids, steering flow magnitude and direction vary for different atmospheric layers, and, therefore, the steering flow for a deep TC might be distinct from the steering flow for a shallow TC in the same environment. For example, simple beta and advection models often produce different TC track forecasts when they are prescribed with deep, medium, and shallow wind profiles and emphasize cases when vortex depth is critical to determine TC motion (Marks 1992). TC track forecasts become more uncertain for moderate amplitudes of deep vertical wind shear when the vortex structure may be difficult to predict (Corbosiero and Molinari 2003; Zhang and Tao 2013; Finocchio et al. 2016). Other studies have shown that TC motion could be significantly altered by intense convection near the vortex and the resulting asymmetry of wind and precipitation fields (Dengler and Reeder 1997; Corbosiero and Molinari 2002; Torn and Davis 2012). In addition, deep vertical wind shear is capable of tilting the TC vortex, and this tilt has small-amplitude implications for TC motion (Flatau et al. 1994). Previous studies have shown that the vertical profile of the environmental wind (e.g., helicity) is a determining factor in the TC vortex response to vertical wind shear (Onderlinde and Nolan 2016; Ryglicki et al. 2018), and the resulting TC vortex structure controls the atmospheric layer responsible for steering the TC. Further, TC positions used to initialize model forecasts are imprecise, especially for weaker TCs without aircraft or land-based observations (e.g., Torn and Snyder 2012; Landsea and Franklin 2013). Uncertainty in the TC position may also translate into differences in the environment with which the vortex interacts and, therefore, may alter TC motion. As Joaquin rapidly intensified from a tropical storm to a major hurricane, its vortex structure changed drastically and, as a result, vortex-environment interactions could have evolved throughout that period. The relationship between the environment and TC vortex (and the resulting feedbacks) is critical to TC motion and must be carefully considered when evaluating track forecasts.

An ensemble prediction system (EPS), or a collection of forecasts verifying at the same time, is an optimal tool to investigate TC track forecast uncertainty and the relative importance of the environment and TC vortex to that uncertainty. Many previous studies used EPSs to evaluate TC track forecast uncertainty and to investigate the range of possible track solutions (Krishnamurti et al. 1997; Zhang 1997; Zhang and Krishnamurti 1997; Cheung and Chan 1999a,b; Zhang and Krishnamurti 1999; Krishnamurti et al. 2000; Cheung 2001; Weber 2003). Recently, the TC research community has developed 
advanced high-resolution EPSs to represent more accurately vortex-environment interactions that could be critical for TC motion. With support from the Hurricane Forecast Improvement Project (HFIP; Gopalakrishnan et al. 2018), the Hurricane Weather Research and Forecasting (HWRF) Model (Gopalakrishnan et al. 2011, 2012, 2013; Bao et al. 2012; Tallapragada et al. 2014; Atlas et al. 2015) was configured as an EPS (HWRF-EPS) to produce high-resolution probabilistic TC forecasts (Zhang et al. 2014). In addition, an advanced version of HWRF, called "basin-scale" HWRF (HWRF-B), is configured with a large outermost domain that improves the simulation of vortex-environment interactions (X. Zhang et al. 2016; Alaka et al. 2017). Configuration options from HWRF-B were integrated with HWRF-EPS to create an experimental EPS for this study.

High track forecast uncertainty for Joaquin has been the subject of several recent studies (Nystrom et al. 2018; Torn et al. 2018; Miller and Zhang 2019; Saunders et al. 2019). Using EPS forecasts from the Weather Research and Forecasting (WRF) Model, Nystrom et al. (2018) found that the largest contributor to the divergence of Joaquin track forecasts was initial condition errors between 600 and $900 \mathrm{~km}$ from the initial TC position. For EPS members that more accurately predicted the longitude of Joaquin at later lead times, initial 700-hPa geopotential heights were higher to the west of the TC and lower to the east. Further, initial 700-hPa meridional wind was more northerly over Joaquin in the more accurate members. As a result, accurate members that tracked farther east were associated with strong lowertropospheric westerly steering flow, whereas members that tracked farther west were associated with strong lower-tropospheric southerly steering flow. In an evaluation of EPS forecasts from the European Centre for Medium-Range Weather Forecasts (ECMWF), Torn et al. (2018) discovered that major differences in the location of Joaquin at $72 \mathrm{~h}$ were associated primarily with the evolution of two synoptic-scale ridges, one to the southwest of Joaquin and the other to the north of Joaquin. In particular, stronger southerly deeptropospheric steering flow and lower 500-hPa geopotential heights led to a Joaquin forecast position that was too far north. Miller and Zhang (2019) also found sensitivity to the synoptic-scale environment to the west of Joaquin. In addition, they asserted that the TC vortex structure was critical to the track forecast, with a deeper vortex necessary for Joaquin to interact correctly with uppertropospheric steering flow. Saunders et al. (2019) corroborated the importance of upper-tropospheric steering flow to Joaquin track forecasts and specifically connected this steering flow with the synoptic-scale ridge to the southwest of Joaquin.
The main goal of this study is to evaluate the relative importance of the environment and the TC vortex to track forecast uncertainty for Hurricane Joaquin at later lead times by using an experimental high-resolution EPS. For the first time, a high-resolution HWRF-based EPS was used to analyze the environment and the TC vortex as factors for TC track forecast uncertainty. In addition, we introduce a new methodology to vary the initial TC location in EPS forecasts and apply it to Hurricane Joaquin. Section 2 describes model configuration options, the experimental design, and methods for TC vortex analysis. Section 3 investigates sources of high track forecast uncertainty for Joaquin, including the environment and TC vortex structure, and tests the importance of the initial TC location to track forecast uncertainty. Conclusions are provided in section 4 .

\section{Model configuration and methodology}

\section{a. HWRF-B modeling system}

HWRF, developed by NOAA/NWS/NCEP and collaborative community partners, is a regional dynamical numerical weather prediction modeling system that is triply nested, storm-centric, and capable of producing high-resolution TC forecasts (Gopalakrishnan et al. 2011, 2012, 2013; Bao et al. 2012; Tallapragada et al. 2014; Atlas et al. 2015). Specifically, all experiments in this study were adapted from HWRF v3.8a, which ran operationally in 2016 (Biswas et al. 2016). HWRF is currently an operational NOAA model that produces reliable guidance for TC track and intensity forecasts (Cangialosi and Franklin 2017). With support from HFIP, the NOAA Atlantic Oceanographic and Meteorological Laboratory (AOML) Hurricane Research Division (HRD) developed HWRF-B as a test bed to improve HWRF forecasts and as a research tool to better understand TC-environment interactions (X. Zhang et al. 2016; Alaka et al. 2017). HWRF-B has unique configuration options, including a large, fixed outermost domain that spans the eastern North Pacific and North Atlantic hurricane basins. Alaka et al. (2017) investigated the benefits of HWRF-B relative to the operational HWRF for TC track forecasts. They demonstrated track improvements in HWRF-B due in part to the large outermost domain that was more capable of accurately predicting TC interactions with the synoptic-scale environment. The large outermost domain configuration option lowered Joaquin position errors when applied to the HWRF model (B. Zhang et al. 2016).

\section{b. HWRF-EPS}

The HWRF-EPS has 20 individual members per forecast and is configured as a triply nested system 


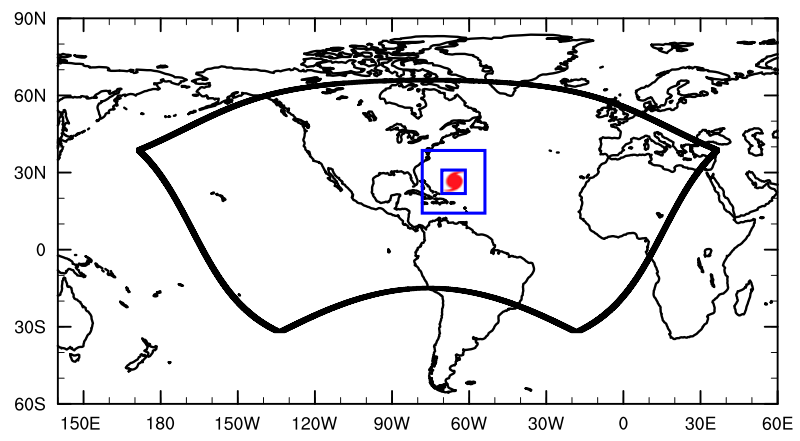

FIG. 1. Schematic of the triply nested domain configuration used in HBE for a forecast initialized at 1200 UTC 29 Sep 2015 (J092912). The large outermost domain (black) is a configuration option used in HWRF-B. The two inner domains (blue) are identical to those used in HWRF-EPS and follow Joaquin throughout the forecast.

with horizontal resolutions of 27,9 , and $3 \mathrm{~km}$ for each domain, respectively. HWRF-EPS perturbations can be classified into three categories: 1) NCEP Global Ensemble Forecast System (GEFS) initial and lateral boundary conditions, 2) stochastic physics perturbations, and 3) initial maximum intensity perturbations of $\pm 3 \mathrm{~m} \mathrm{~s}^{-1}$ (Zhang et al. 2014). GEFS provides large-scale flow perturbations at the initial time and throughout model integration (i.e., every $6 \mathrm{~h}$ ), with a unique GEFS member serving as initial and lateral boundary conditions for each HWRF-EPS member. Initial perturbations in GEFS are created through the rescaled ensemble transform method that identifies the covariance associated with forecast error (Wei et al. 2006, 2008). Throughout the GEFS integration, stochastic perturbations are added to model tendency terms to allow for reasonable variance within each forecast (Hou et al. 2006). These perturbations are introduced into the HWRF-EPS outermost domain through the lateral boundaries. No modifications are made to GEFS initial and lateral boundary conditions by the HWRF-EPS.

Model physics that are stochastically perturbed at each call during the HWRF-EPS integration include 1) the convective trigger function within the simplified Arakawa-Schubert (SAS) cumulus parameterization scheme (Pan and Wu 1995),2) the planetary boundary layer (PBL) height within the Global Forecast System (GFS) PBL scheme (Troen and Mahrt 1986), and 3)

TABLE 1. Descriptions and summaries for HBE experiments.

\begin{tabular}{|c|c|c|}
\hline Experiment & Description & Configuration Summary \\
\hline HBE1 & Control & $\begin{array}{l}\text { HWRF-EPS options } \\
\text { HWRF-B outermost domain } \\
80 \text { members } \\
\text { GEFS initial conditions ON } \\
\text { Stochastic physics perturbations ON } \\
\text { Initial intensity perturbations ON }\end{array}$ \\
\hline HBE2 & Physics perturbations OFF & $\begin{array}{l}\text { HWRF-EPS options } \\
\text { HWRF-B outermost domain } \\
80 \text { members } \\
\text { GEFS initial conditions ON } \\
\text { Stochastic physics perturbations OFF } \\
\text { Initial intensity perturbations OFF }\end{array}$ \\
\hline HBE3 & $\mathrm{NE}$ initial conditions + ILV technique + physics perturbations $\mathrm{OFF}$ & $\begin{array}{l}\text { HWRF-EPS options } \\
\text { HWRF-B outermost domain } \\
25 \text { members (ILV technique) } \\
\text { "NE" GEFS initial conditions ON } \\
\text { Stochastic physics perturbations OFF } \\
\text { Initial intensity perturbations OFF }\end{array}$ \\
\hline HBE4 & NW initial conditions + ILV technique + physics perturbations OFF & $\begin{array}{l}\text { HWRF-EPS options } \\
\text { HWRF-B outermost domain } \\
25 \text { members (ILV technique) } \\
\text { "NW" GEFS initial conditions ON } \\
\text { Stochastic physics perturbations OFF } \\
\text { Initial intensity perturbations OFF }\end{array}$ \\
\hline HBE5 & $\mathrm{NE}$ initial conditions + ILV technique + physics perturbations ON & $\begin{array}{l}\text { HWRF-EPS options } \\
\text { HWRF-B outermost domain } \\
25 \text { members (ILV technique) } \\
\text { "NE" GEFS initial conditions ON } \\
\text { Stochastic physics perturbations ON } \\
\text { Initial intensity perturbations ON }\end{array}$ \\
\hline
\end{tabular}


TABLE 2. Model initialization times and abbreviations for HBE experiments.

\begin{tabular}{cc}
\hline \hline Model initialization time & Abbreviation \\
\hline 1200 UTC 29 Sep 2015 & J092912 \\
0000 UTC 30 Sep 2015 & J093000 \\
1200 UTC 30 Sep 2015 & J093012 \\
0000 UTC 1 Oct 2015 & J100100 \\
\hline
\end{tabular}

the drag coefficient $C_{D}$ within the modified Geophysical Fluid Dynamics Laboratory (GFDL) surface-layer scheme (Sirutis and Miyakoda 1990). The convective trigger function supports convection when the pressure difference (DP), defined as the difference between the level where convection initiates (usually the surface) and the level of free convection, is less than an arbitrary value between 120 and $180 \mathrm{hPa}$. Random perturbations between $\pm 50 \mathrm{hPa}$ are added to DP to simulate the impact of unresolved subgrid-scale processes. The PBL height impacts the shape and intensity of the TC nearsurface inflow layer (e.g., Zhang et al. 2011), and $C_{D}$ controls dissipation due to friction. Both PBL height and $C_{D}$ are randomly scaled by factors between $\pm 20 \%$ based on observations. Refer to Zhang et al. (2014) for details about these HWRF-EPS perturbations.

The TC vortex is directly modified via random initial maximum intensity perturbations within $\pm 3 \mathrm{~m} \mathrm{~s}^{-1}$. These perturbations account for uncertainty in the observed maximum intensity and are especially important in the absence of in situ aircraft observations in the TC inner core (e.g., Landsea and Franklin 2013), as was the case for Joaquin. Interested readers are directed to Biswas et al. (2016) for details about TC vortex initialization in HWRF.

\section{c. Experimental design}

In this study, we configured the HWRF-EPS system with the large outermost domain option from HWRF-B to create an experimental HWRF-B EPS (HBE; Fig. 1). The HWRF-B outermost domain is large enough to isolate most TCs from errors induced by the lateral boundary throughout a 5-day forecast (e.g., Durran and Gingrich 2014; Warner et al. 1997). Consequently, the evaluation described herein focused on the impact of initial perturbations instead of the impact of perturbed lateral boundary conditions. Five HBE experiments were configured, with the control experiment (HBE1) featuring identical configuration options to HWRF-EPS, except for a larger outermost domain (Table 1). The horizontal resolutions for the three HBE domains are 27,9 , and $3 \mathrm{~km}$, respectively, consistent with HWRF-EPS. Four separate sets of 5-day forecasts $(20$ members per set; 80 total members) were produced for HBE1 and HBE2 during the critical intensification stage of Hurricane Joaquin,

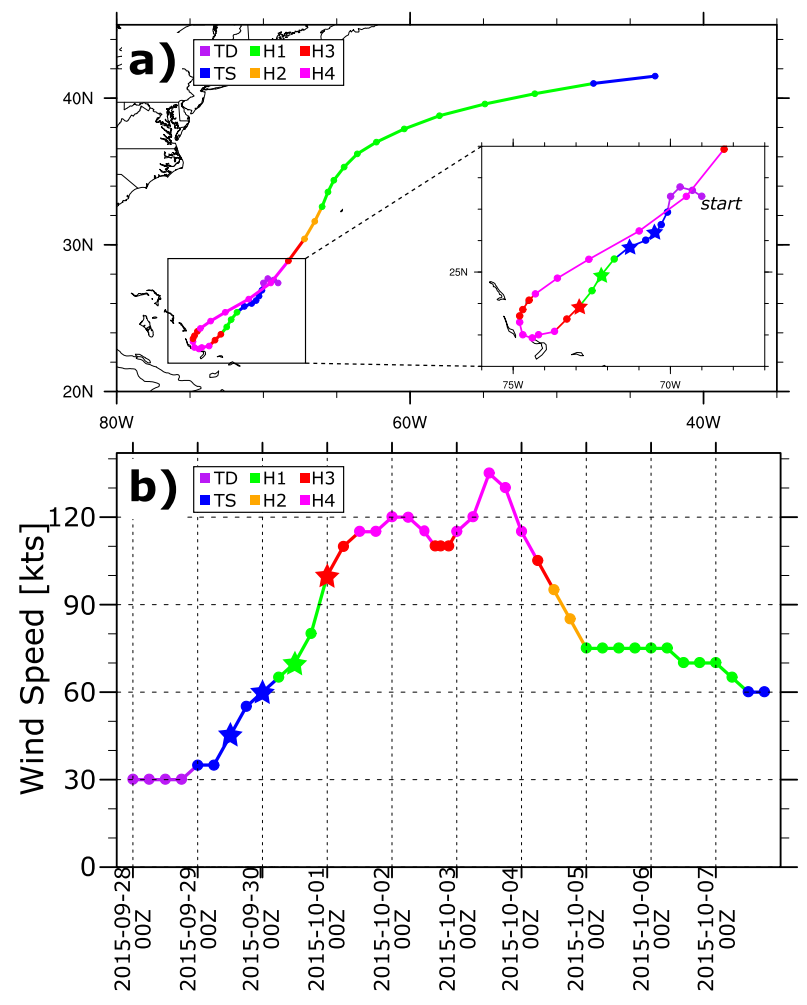

FIG. 2. (a) Joaquin (2015) lifetime track from BEST, color-coded by classification on the Saffir-Simpson scale (i.e., tropical depression, tropical storm, category 1-4). (b) As in (a), except for lifetime intensity (kt). The four model initialization times evaluated in this study are marked by stars: 1200 UTC 29 Sep 2015 forecast (J092912), 0000 UTC 30 Sep 2015 (J093000), 1200 UTC 30 Sep 2015 (J093012), and 0000 UTC 1 Oct 2015 (J100100).

when track uncertainty was high. To reduce correlation between members and to minimize differences in available data, the model initialization times for these four forecast cycles were separated by $12 \mathrm{~h}$ (Table 2): 1200 UTC 29 September 2015 (J092912), 0000 UTC 30 September 2015 (J093000), 1200 UTC 30 September 2015 (J093012), and 0000 UTC 1 October 2015 (J100100). During these model initialization times, Joaquin moved slowly to the southwest and intensified from a tropical storm to a category 3 major hurricane (Fig. 2). For HBE3, HBE4, and HBE5, one set of 5-day forecasts (25 total members) was initialized at J092912 for each experiment (see section 3d).

The investigation identified factors that contributed to TC track forecast uncertainty, including the synoptic-scale environment and the TC vortex. The GFS analysis (GFSA; http://www.emc.ncep.noaa.gov/GFS/doc.php) was used as the best estimate of observations to evaluate the accuracy of the environment in HBE forecasts. The environment was analyzed primarily through layer-mean winds (i.e., steering flow) and 500-hPa geopotential height. In some analyses, the TC vortex 

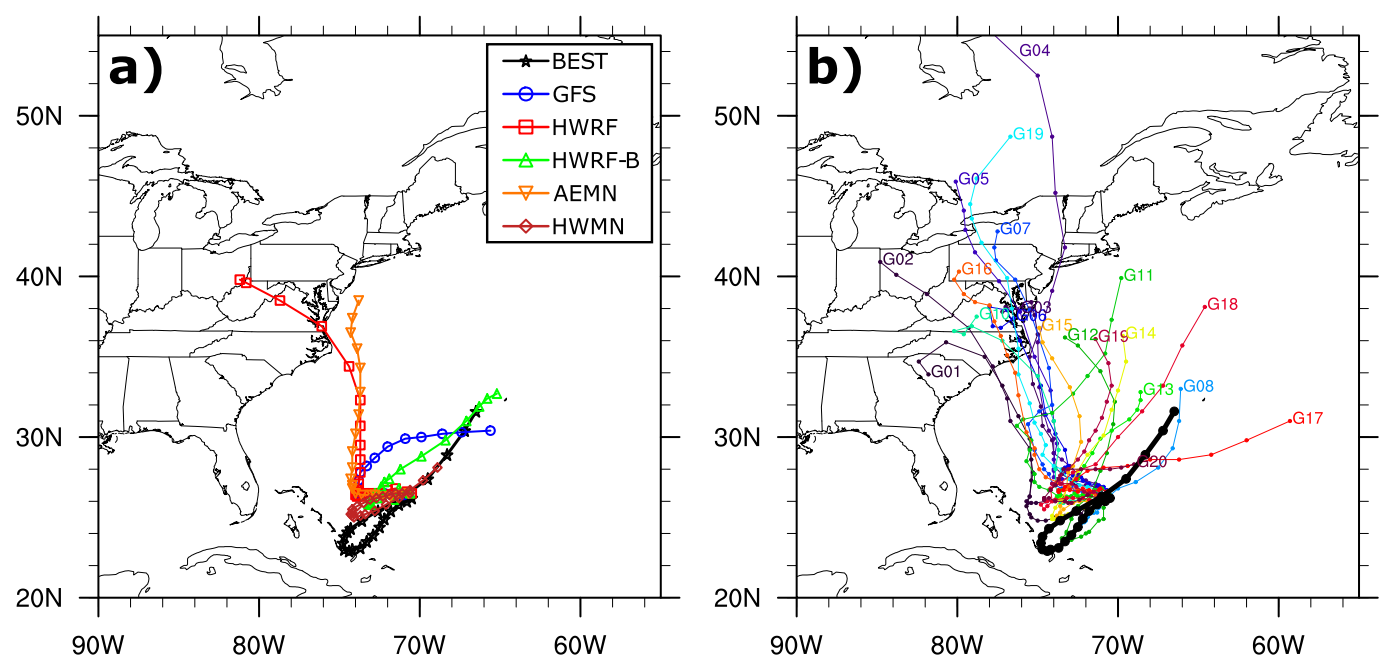

FIG. 3. (a) For a forecast initialized at 1200 UTC 29 Sep 2015 (J092912), Joaquin track forecasts are shown for GFS (blue circle), HWRF (red square), HWRF-B (green triangle), AEMN (orange delta), and HWMN (brown diamond). (b) GEFS track forecasts initiated at 1200 UTC 29 Sep 2015 (J092912). BEST (black) represents the observed track in both panels.

was removed from the environmental flow by following the methodology described in Kurihara et al. (1993) and, therefore, allowed for the independent evaluation of the environment.

Joaquin's center positions and maximum intensities at all valid times were determined from the NHC postprocessed best track (BEST; Rappaport et al. 2009). "TCVitals," referred to as the working best track and determined by NHC based on available observations to initialize the TC vortex in real-time NOAA models (http:// www.emc.ncep.noaa.gov/HWRF/tcvitals-draft.html), provided TC characteristics at model initialization times. We note that BEST and TCVitals are not identical because the

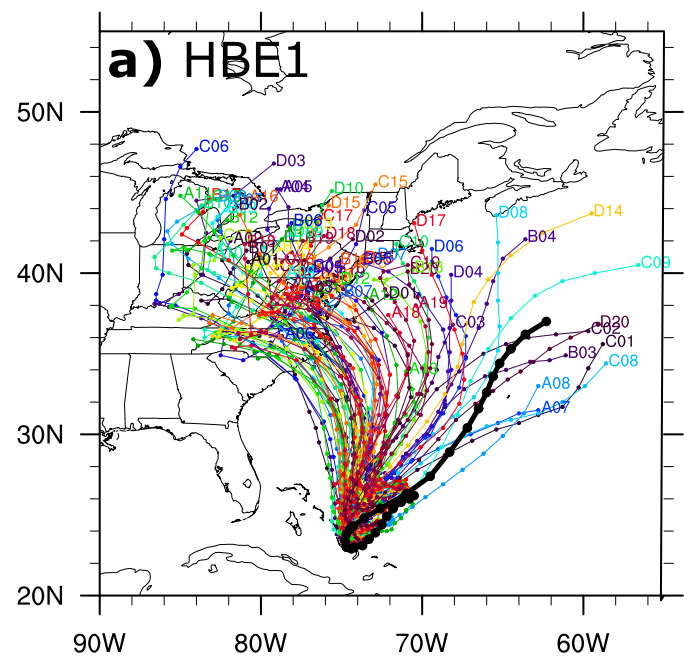

former includes observations that may not be available when NOAA models are initialized. BEST and TCVitals have uncertainties that have been mostly constant over the years despite improved observations and analysis techniques (Torn and Snyder 2012; Landsea and Franklin 2013). It should be noted that the uncertainty of these datasets increases in the absence of ground-based and aircraft observations, as was the case for Joaquin during the study period.

\section{d. Vortex analysis}

The vertical structure of the TC vortex was evaluated by converting to polar cylindrical coordinates,

FIG. 4. Joaquin track forecasts initiated at 1200 UTC 29 Sep 2015 (J092912, A), 0000 UTC 30 Sep 2015 (J093000, B), 1200 UTC 30 Sep 2015 (J093012, C), and 0000 UTC 1 October 2015 (J100100, D) for (a) HBE1 and (b) HBE2. BEST is marked by a black line.

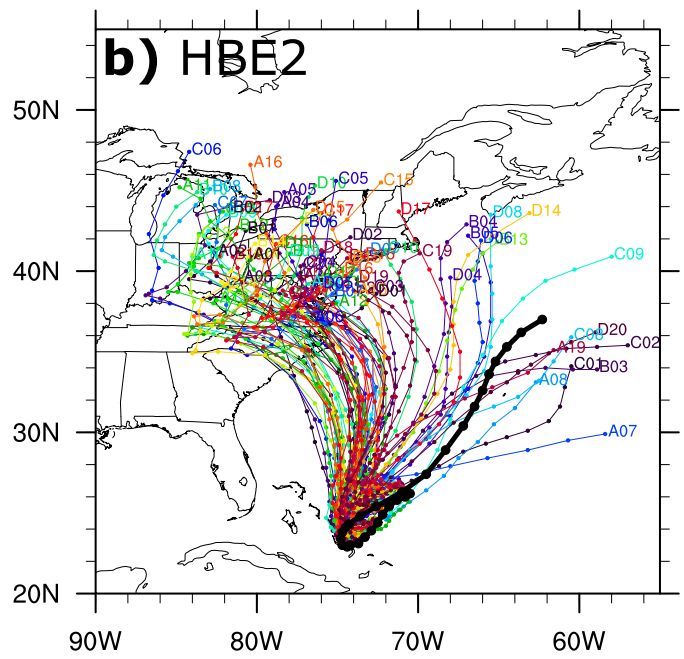


TABLE 3. Track error statistics $(\mathrm{km})$ for all HBE experiments at a lead time of $96 \mathrm{~h}$. HBE1 and HBE2 have 80 total members. HBE3, HBE4, and HBE5 have 25 total members.

\begin{tabular}{crrrrr}
\hline \hline Experiment & Mean & Median & Standard deviation & 25th percentile & 75th percentile \\
\hline HBE1 & 1109.7 & 1164.4 & 520.0 & 639.8 & 1477.2 \\
HBE2 & 1116.0 & 1173.1 & 527.2 & 674.0 & 1495.3 \\
HBE3 & 427.4 & 428.1 & 48.4 & 402.0 & 456.0 \\
HBE4 & 1224.5 & 1263.8 & 115.3 & 1216.2 & 1280.5 \\
HBE5 & 409.9 & 414.3 & 50.7 & 383.4 & 427.6 \\
\hline
\end{tabular}

azimuthally averaging over all angles, and analyzing the result as a function of radius versus height between 1000 and $200 \mathrm{hPa}$. To account for vortex tilt, the TC surface center was used as a starting point and the center at each level above was independently calculated by a minimum centroid analysis of geopotential height. Therefore, the resulting vertical coordinate became a vortex-following coordinate with altitude.

Due to the subjective nature of TC vortex depth, it was defined using two independent methods. Vortex depth was first defined as a function of vertical decay of the maximum wind (Hazelton et al. 2018). In this definition, the vortex depth is the highest altitude pressure level at which the maximum azimuthally averaged wind is $\geq 75 \%$ of the $850-\mathrm{hPa}$ maximum azimuthally averaged wind. For major hurricanes, the threshold is relaxed to $65 \%$. This definition is referred to as the "wind decay depth." Vortex depth was also defined as a function of vortex tilt. In this definition, the vortex depth is the highest altitude pressure level at which the geopotential height centroid center is within $1 \mathrm{~km} \mathrm{hPa}^{-1}$ of the center below it. For pressure levels that are $25 \mathrm{hPa}$ apart, the upper TC center must be $\leq 25 \mathrm{~km}$ from the lower TC center for it to be considered a part of the same vortex. This definition is referred to as the "centroid center depth."

\section{Results}

\section{a. Joaquin track forecast uncertainty}

NOAA numerical weather prediction models, both deterministic solutions and EPS averages, produced vastly different track forecasts for Joaquin, especially as the TC drifted to the southwest near the Bahamas
(Fig. 3a). For the J092912 forecast (see Table 2), 120-h track forecast locations from deterministic NOAA models spanned from near Bermuda (e.g., GFS, HWRF-B) to West Virginia (e.g., HWRF). None of these model forecasts captured the full southwest extent of Joaquin's track. Instead of propagating to the southwest, Joaquin was predicted to move slowly to the west or west-southwest in the first $48 \mathrm{~h}$ of these model forecasts, resulting in position errors to the north at early lead times. However, the southwest loop at early lead times was not a requirement for small track errors at later lead times, supported by HWRF-B and GFS forecasts. Interestingly, the GEFS mean (AEMN) agreed with the HWRF deterministic track forecast, and the HWRF-EPS mean (HWMN) was consistent with the GFS deterministic track forecast.

AEMN alone failed to convey the track uncertainty associated with GEFS forecasts that was of crucial importance to TC forecasters and interests along the U.S. East Coast. GEFS forecasts for J092912 revealed high track uncertainty, with 120 -h locations ranging from $85^{\circ}$ to $59^{\circ} \mathrm{W}$ and from $28^{\circ}$ to $56^{\circ} \mathrm{N}$ (Fig. 3b). Furthermore, AEMN track error was in excess of $1000 \mathrm{~km}$ at $120 \mathrm{~h}$ (see Fig. 3a), a consequence of most GEFS members being north and west of BEST at longer lead times. In particular, more than half of GEFS members predicted a U.S. landfall within $120 \mathrm{~h}$ (12 of 20), and only two members predicted Joaquin positions to the right of BEST. Only one GEFS member (G12) came close to replicating the southwest extent of Joaquin. Yet, this member was headed toward the United States by $120 \mathrm{~h}$, and it will be shown that the southwest loop at early lead times was not a necessary condition for realistic Joaquin track forecasts at later lead times.

TABLE 4. Track error statistics (km) for all HBE experiments at a lead time of $120 \mathrm{~h}$. HBE1 and HBE2 have 80 total members. HBE3, HBE4, and HBE5 have 25 total members.

\begin{tabular}{crrcrr}
\hline \hline Experiment & Mean & Median & Standard deviation & 25th percentile & 75th percentile \\
\hline HBE1 & 1251.8 & 1240.4 & 467.0 & 959.3 & 1639.6 \\
HBE2 & 1233.3 & 1257.7 & 488.4 & 914.0 & 1618.1 \\
HBE3 & 324.9 & 332.7 & 35.7 & 298.2 & 342.7 \\
HBE4 & 1636.9 & 1638.4 & 50.6 & 1614.8 & 1652.5 \\
HBE5 & 308.6 & 306.1 & 39.7 & 281.8 & 321.2 \\
\hline
\end{tabular}



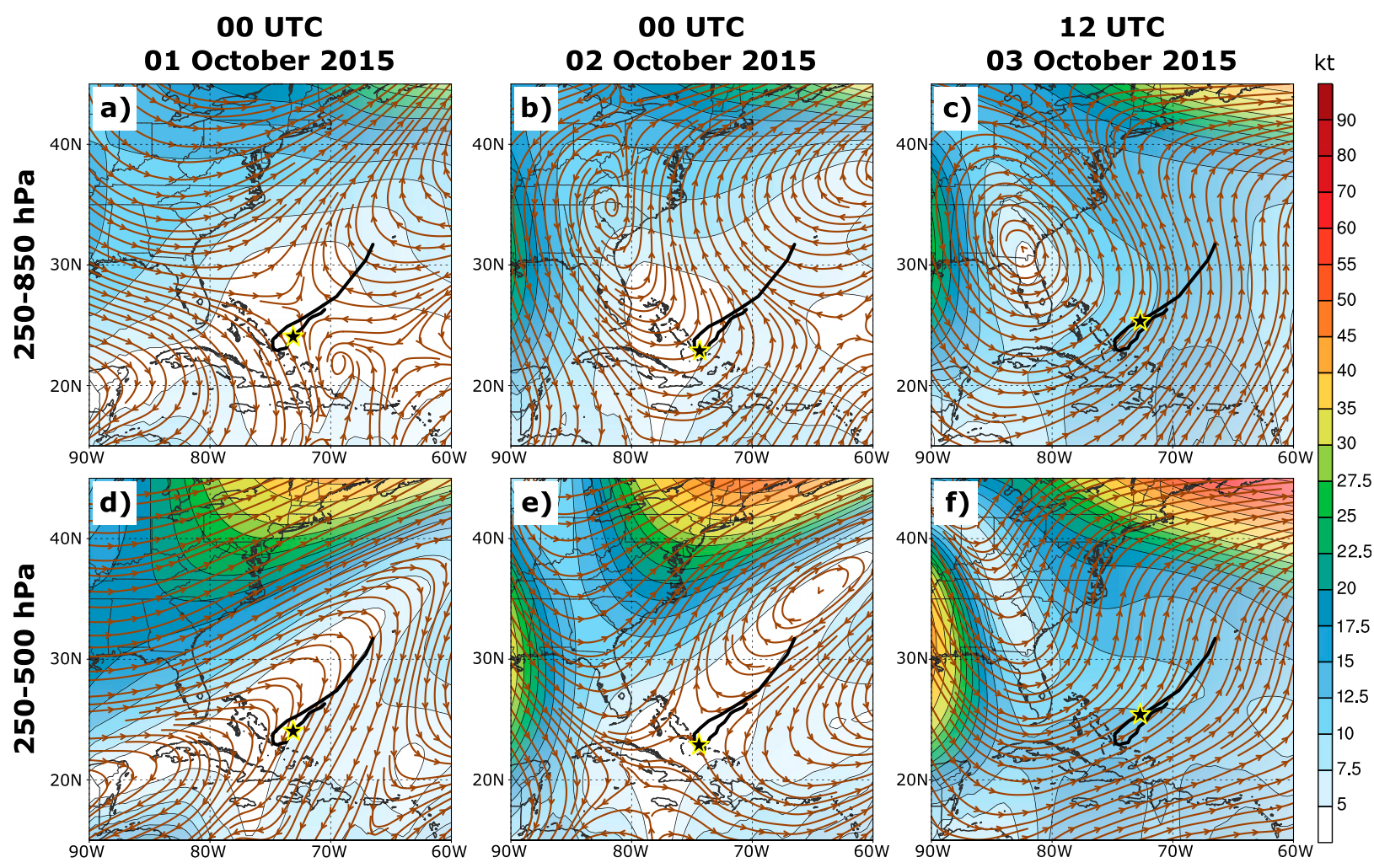

FIG. 5. (top) The evolution GFSA environmental 250-850-hPa steering flow amplitude (kt; shaded) and direction (streamlines). (bottom) As in (a)-(c), but for environmental 250-500-hPa steering flow. Valid times shown are (a),(d) 0000 UTC 1 Oct 2015, (b),(e) 0000 UTC 2 Oct 2015, and (c),(f) 1200 UTC 3 Oct 2015. BEST is shown in black, and a black/yellow star marks the location of Joaquin at the corresponding valid time.

Track forecast uncertainty was evaluated in HBE forecasts for Joaquin. The control version of HBE used the same configuration options as HWRF-EPS, except for the large, fixed outermost domain (HBE1; Table 1). HBE1 was configured with perturbations to the environment and the TC vortex, including stochastic physics perturbations and initial intensity perturbations. Most (15 of 20) HBE1 J092912 forecasts produced a U.S. landfall by $120 \mathrm{~h}$ (Fig. 4a). Furthermore, the inclusion of additional forecast cycles (i.e., J093000, J093012, and J100100) did not significantly change the percentage of landfalling HBE1 members (59 of 80). Overall, these four forecast cycles produced similar track forecast uncertainty, with some members propagating toward the United States and others propagating toward the central North Atlantic.

Despite the inclusion of TC vortex perturbations, intensity forecasts were consistent across HBE1 members, with all but one member attaining maximum wind speeds greater than $100 \mathrm{kt}\left(1 \mathrm{kt} \approx 0.51 \mathrm{~m} \mathrm{~s}^{-1}\right)$ (not shown). Most HBE1 members forecasted maximum intensity prior to 1200 UTC 3 October 2015, when the maximum actually occurred in BEST (see Fig. 2b). Therefore, the western North Atlantic was conducive for intensification and
Joaquin appeared likely to attain major hurricane status, regardless of the specific characteristics of its vortex and its track.

To test the impact of environmental perturbations alone on track spread in Joaquin forecasts, stochastic physics perturbations and initial maximum intensity variations were turned off (HBE2; Table 1; Fig. 4b). However, HBE1 and HBE2 track forecasts were statistically indiscernible from one another, including at later lead times. At $96 \mathrm{~h}$, important track error statistics for HBE1 and HBE2 forecasts were within $5 \%$ of one another (Table 3). Mean track errors for both experiments were greater than $1100 \mathrm{~km}(1110 \mathrm{vs} 1116 \mathrm{~km})$ with standard deviations greater than $500 \mathrm{~km}(520 \mathrm{vs} 527 \mathrm{~km})$, highlighting large track spread despite most members being positioned too far northwest relative to BEST. At $120 \mathrm{~h}$, track error statistics were also within $5 \%$ for the two experiments, with mean track errors greater than $1200 \mathrm{~km}$ and standard deviations greater than $450 \mathrm{~km}$ (Table 4). Furthermore, a nearly identical set of track forecasts from HBE2 (58 of 80) made landfall in the United States. Track forecasts for identical members in HBE1 and HBE2 were qualitatively similar. For example, the 


\section{UTC 02 October 2015}

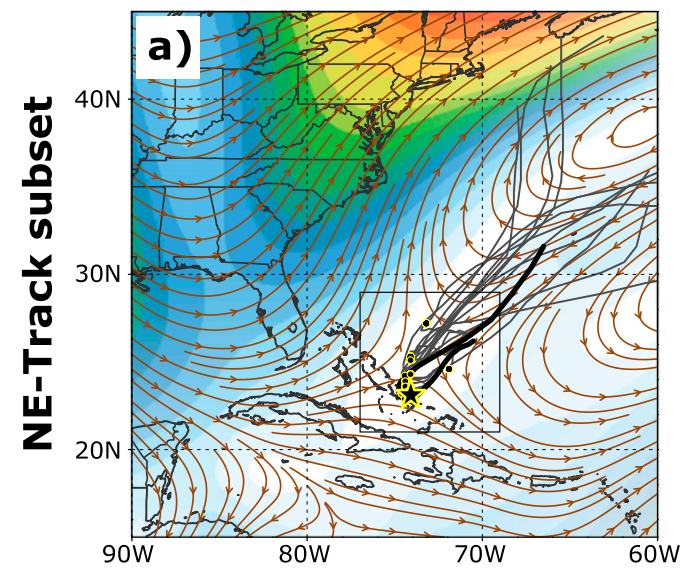

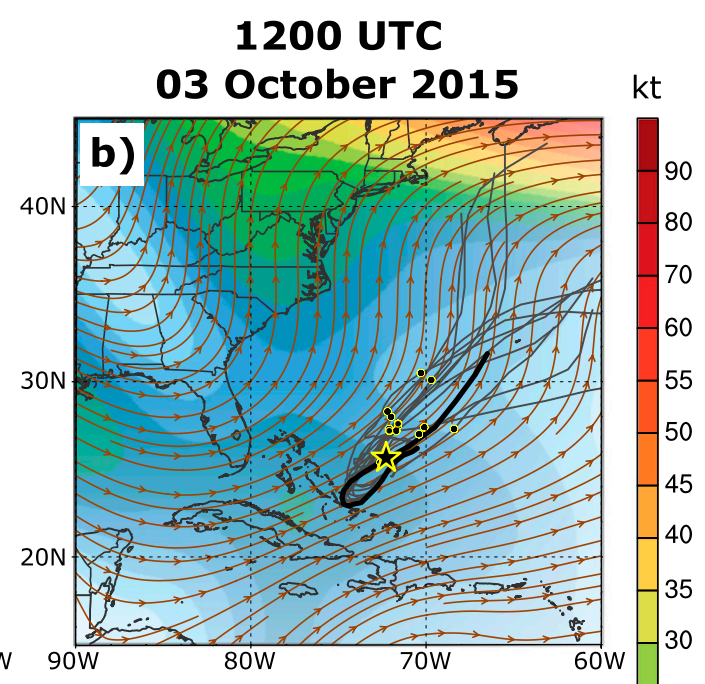

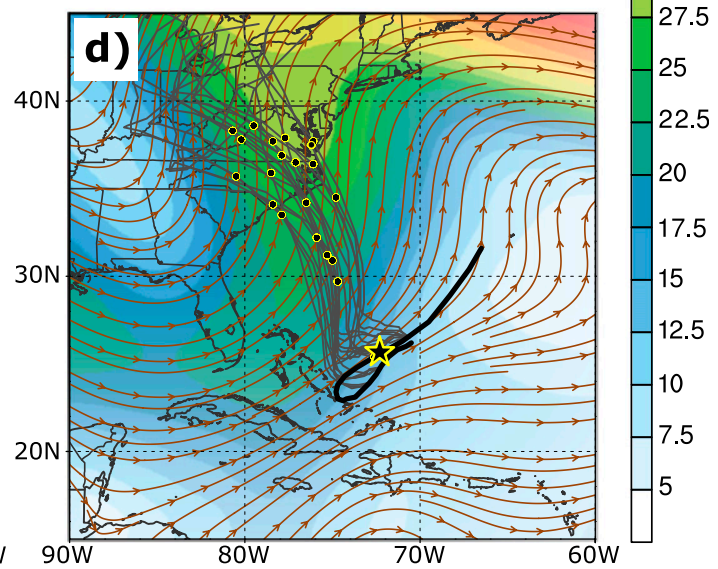

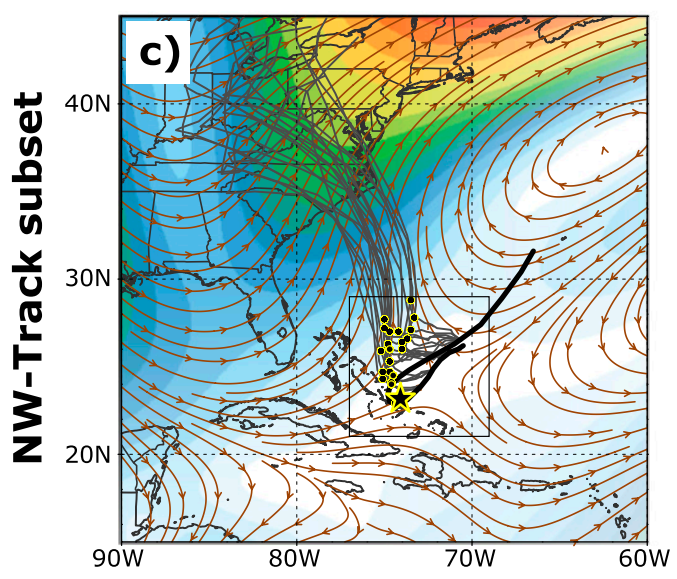

FIG. 6. Environmental 250-500-hPa steering flow (kt) composites for (a) the NE-track subset at 0000 UTC 2 Oct 2015, (b) the NE-track subset at 1200 UTC 3 Oct 2015, (c) the NW-track subset at 0000 UTC 2 Oct 2015, and (d) the NW-track subset at 1200 UTC 3 Oct 2015. BEST is shown in black, and a star marks the BEST location of Joaquin at the corresponding valid time. Individual HBE member tracks are shown in gray and the corresponding location is marked by a black/yellow circle. Streamlines represent the steering direction and shading represents the steering amplitude. The boxes in (a) and (c) correspond the zoomed region shown in Fig. 7.

two versions of member $\mathrm{C} 09$ were positioned to the northeast of the BEST position at $120 \mathrm{~h}$, and the two versions of member $\mathrm{C} 06$ were positioned near Lake Superior at $120 \mathrm{~h}$. Except for changes in a few outliers, the spread of HBE2 intensity forecasts was also approximately the same as in HBE1 (not shown). Overall, the similarity between these two experiments indicated that stochastic physics perturbations and initial maximum intensity variations were not major factors in track forecast uncertainty for Joaquin. Therefore, HBE2 was the focus of the evaluations in the following two subsections so that differences could be attributed to the GEFS initial conditions.

\section{b. Impact of the synoptic-scale environment}

The synoptic-scale environment over the North Atlantic Ocean and North America evolved rapidly from
0000 UTC 1 October 2015 to 1200 UTC 3 October 2015 and significantly influenced the steering flow near Joaquin (Fig. 5). Joaquin became embedded in weak steering between a weakening ridge over the central North Atlantic, a midlatitude trough approaching from the west, and an upper-tropospheric trough to its east. Consequently, Joaquin meandered near the Bahamas for two days before turning sharply to the northeast and accelerating to the central North Atlantic. Typically, the motion of intensifying TCs is best described by the deeptropospheric $(250-850 \mathrm{hPa})$ steering flow (e.g., Figs. 5ac). However, the deep-tropospheric steering flow was inconsistent with the motion of Joaquin, especially from 0000 UTC 2 October to 1200 UTC 3 October 2015, when this flow would have steered Joaquin toward the U.S. East Coast. After careful evaluation of many 

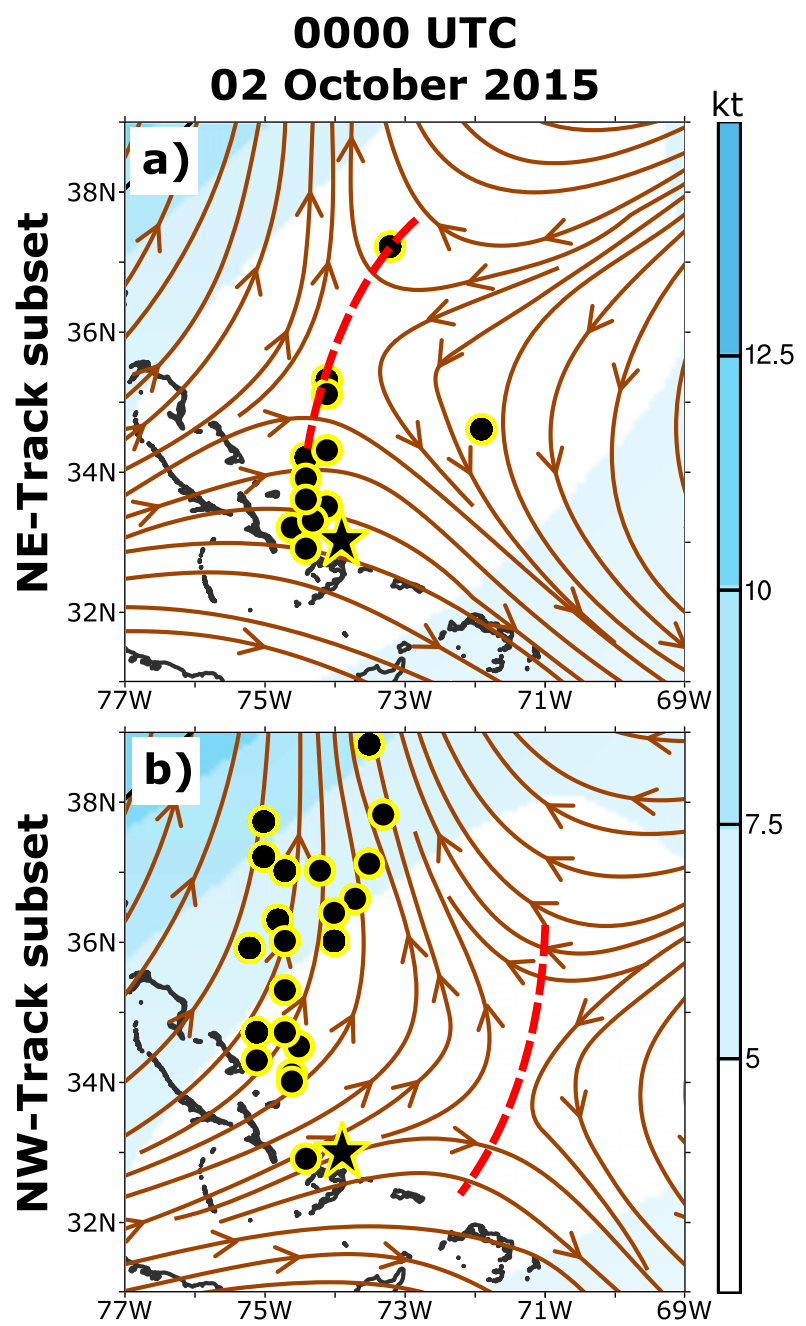

FIG. 7. Environmental 250-500-hPa steering flow (kt) composites at 0000 UTC 2 Oct 2015 for (a) the NE-track subset and (b) the NW-track subset. This region is marked by a box in Figs. $6 \mathrm{a}$ and $6 \mathrm{c}$. A star marks the BEST location of Joaquin at this time. The corresponding position of individual HBE members is marked by a black/yellow circle. Streamlines represent the steering direction and shading represents the steering amplitude. The red dashed line represents the col axis in each composite.

atmospheric layers, the upper-tropospheric (250$500 \mathrm{hPa}$ ) steering flow was found to best describe the motion of Joaquin over this critical 60 -h period (Figs. 5d-f), consistent with previous findings (Miller and Zhang 2019; Saunders et al. 2019). In particular, an upper-tropospheric col that developed near $25^{\circ} \mathrm{N}$ and $75^{\circ} \mathrm{W}$ at 0000 UTC 2 October 2015 weakened the steering flow near Joaquin and played a critical role in the ultimate trajectory of this TC (Fig. 5e).

The col was connected to four synoptic-scale features: 1) a deep-tropospheric trough to the northwest of Joaquin over North America, 2) a deep-tropospheric ridge to the northeast of Joaquin over the central North Atlantic, 3) an upper-tropospheric trough to the east of Joaquin, and 4) a weak upper-tropospheric ridge to the south of Joaquin (Figs. 5b,e). By 1200 UTC 3 October 2015, the North American trough and the North Atlantic ridge progressed far enough eastward that the upper-tropospheric steering flow was predominantly directed to the northeast (Fig. 5f). Conversely, the deeptropospheric steering flow was predominantly directed to the north-northwest and would have steered Joaquin toward the United States (Fig. 5c).

Given the complicated evolution of the synoptic-scale environment near Joaquin, HBE2 members with large and small track errors were compared with one another and to GFSA (Fig. 5) to identify key similarities and differences. Specifically, HBE2 forecasts were stratified by $96-$ and 120 -h track errors to identify the best and worst track forecasts at later lead times. Twelve track forecasts were in the lower quartile of errors at both lead times and represented forecasts that correctly propagated Joaquin to the northeast (i.e., NE-track subset). Conversely, 20 track forecasts were in the upper quartile of errors at both lead times and represented Joaquin forecasts that incorrectly predicted a U.S. landfall (i.e., NW-track subset). Composites were created based on valid times, accounting for different initialization times in HBE2 forecasts. These composites were used to identify major differences between the environment and TC vortex (see section 3c, as well) in the two groups. We note that each subset included at least one member from each model initialization time. The use of four different initialization times allowed for the significant increase in the number of members within each subset. As noted earlier, these initialization times produced similar track spread uncertainty at later lead times, with some track forecasts associated with small errors and others associated with large errors. Most of the NE-track members were initialized at the two later times $(67 \%)$ and most of the NW-track members were initialized at the two earlier times $(65 \%)$, a caveat of mixing multiple initialization times.

As observed in GFSA, the location of the uppertropospheric col at 0000 UTC 2 October 2015 appeared to be crucial to the ultimate motion of Joaquin in HBE forecasts (Figs. 6a,c and 7). The location of the uppertropospheric col was different in the two subsets even though it was connected to the same four synoptic-scale features that were identified in GFSA. In the NE-track subset composite, the col was positioned in nearly the same location as in GFSA $\left(74^{\circ} \mathrm{W}\right)$, and, in the NW-track subset composite, the col was located $3^{\circ}$ farther east $\left(71^{\circ} \mathrm{W}\right)$. Although NE-track members were characterized by small track errors at later lead times, this did not 


\section{UTC 02 October 2015}

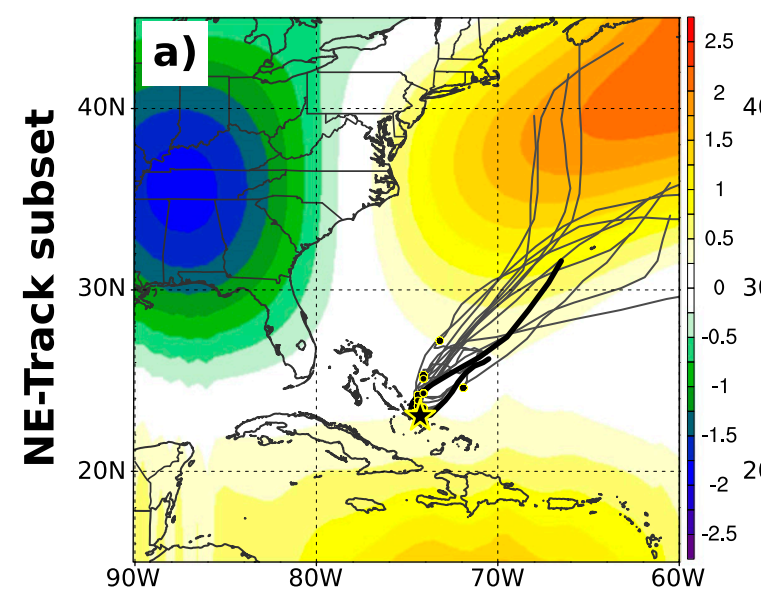

\section{UTC 03 October 2015}

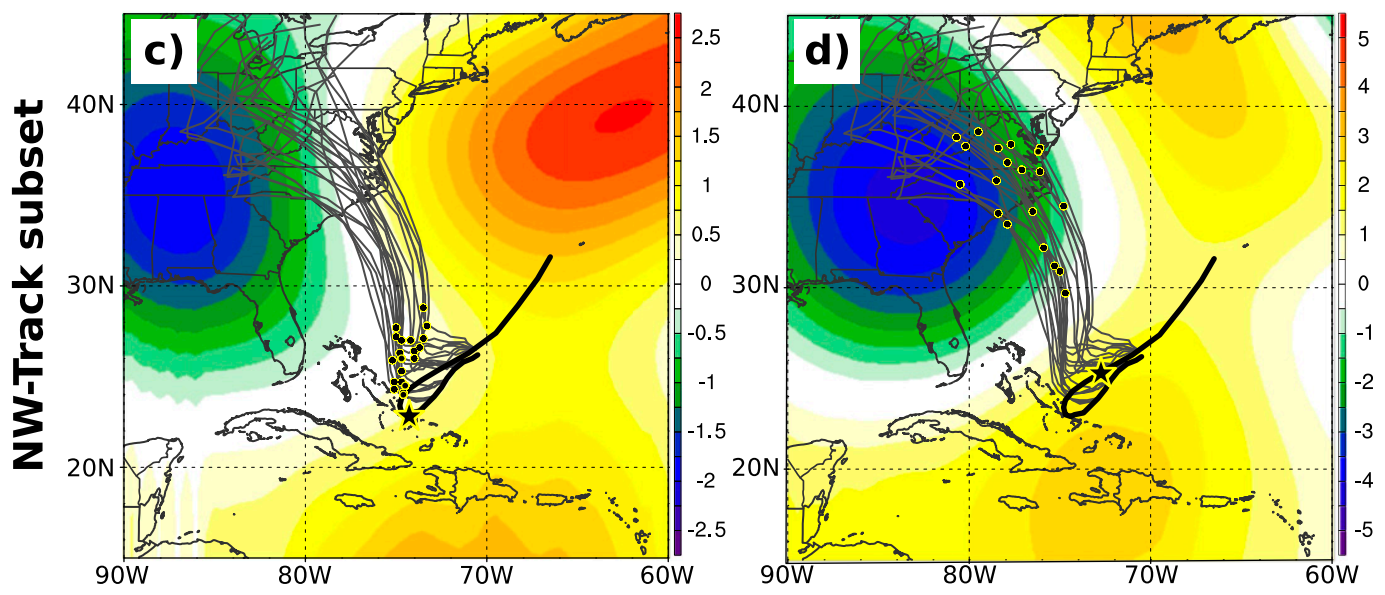

FIG. 8. Environmental 500-hPa geopotential height errors (gpdm), calculated by taking the differences between each composite and GFSA for each corresponding valid time. Shown are (a) the NE-track composite minus GFSA at 0000 UTC 2 Oct 2015, (b) as in (a), but for 1200 UTC 3 Oct 2015, (c) the NW-track composite minus GFSA at 0000 UTC 2 Oct 2015, and (d) as in (c), but for 1200 UTC 3 Oct 2015. BEST is shown in black, with the current location of Joaquin marked by a black/yellow star. Black/yellow circles mark the current location of Joaquin in each member at the corresponding valid time. Note: the shading interval of the two days differs.

necessarily translate into small track errors at early lead times. In fact, comparing Joaquin position forecasts valid at 0000 UTC 2 October 2015 revealed that the full southwest loop was not a necessary condition for NEtrack members (Figs. 6a and 7a). NE-track members were generally located farther south than NW-track members were (Fig. 7). However, the location of the col axis and the corresponding synoptic-scale evolution in each subset was far more important than track errors at earlier lead times. Indeed, all NE-track members were embedded within the weak steering flow $(<5 \mathrm{kt})$ associated with the col, while all NW-track members were embedded in southerly steering flow to the west of the col (Fig. 7). By 1200 UTC 3 October 2015, both subsets showed that the North American trough and the North
Atlantic ridge were the dominant synoptic-scale features steering Joaquin (Figs. 6b,d). Steering flows in the NE-track subset were generally consistent with GFSA (cf. with Fig. 5f), including southerly flow less than $20 \mathrm{kt}$ near $75^{\circ} \mathrm{W}$ associated with the ridge being positioned farther east.

Geopotential height errors at $500 \mathrm{hPa}$ with respect to GFSA revealed some key similarities and differences between the NE-track and NW-track composites at 0000 UTC 2 October 2015 (Figs. 8a,c). Relative to GFSA, both subsets similarly showed a deeper trough over North America, a stronger ridge to the northeast of Joaquin, and a stronger ridge to the south of Joaquin. However, compared with the NW-track subset, the NEtrack subset included a trough over North America 


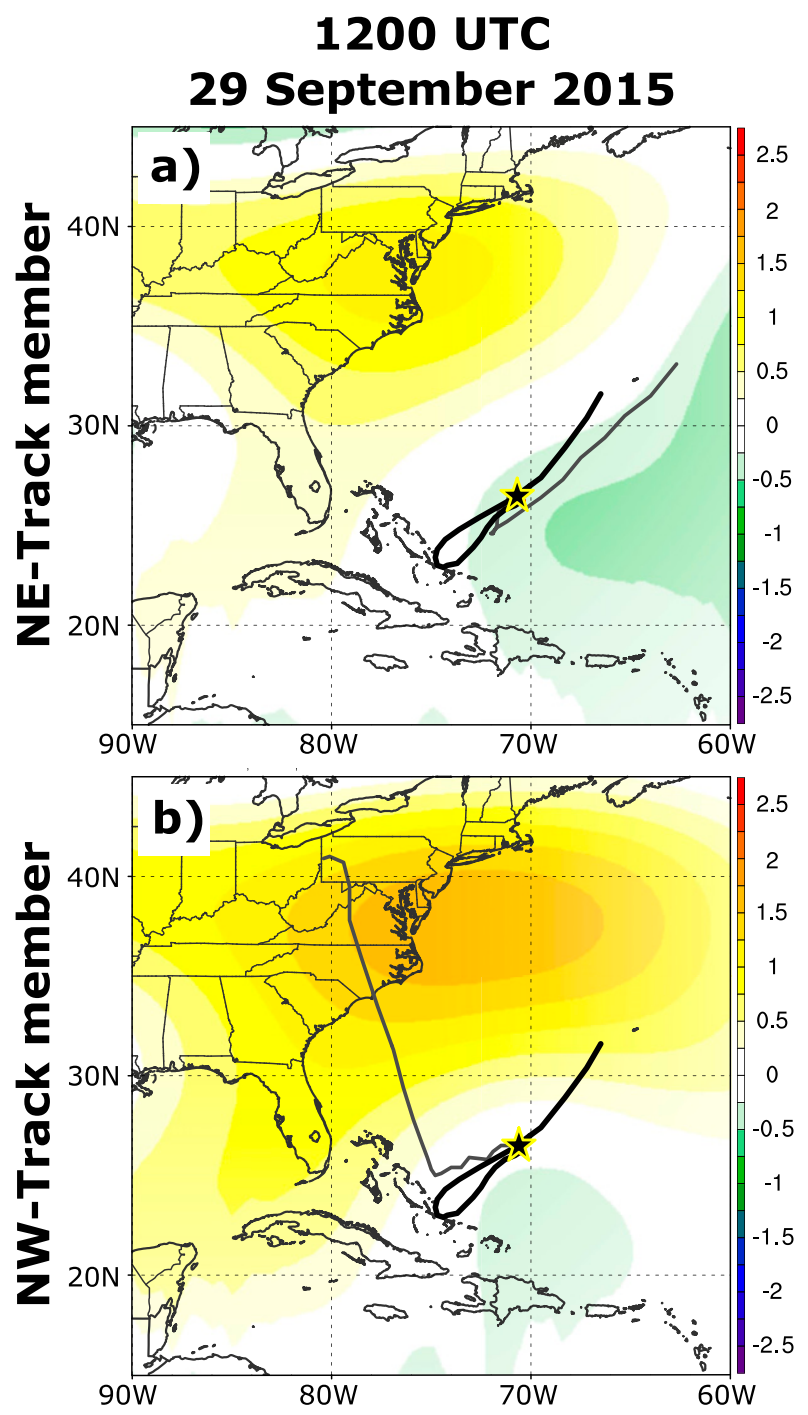

FIG. 9. For the J092912 forecast, initial 500-hPa geopotential height errors (gpdm) calculated by taking the difference between GFSA and (a) the NE-track member and (b) the NW-track member. BEST is shown as a black line and the respective HBE member is represented by a thinner, gray line. A black/yellow star marks the initial location of Joaquin.

that did not dig as far south and a weaker ridge to the northeast of Joaquin. Height errors to the east of Joaquin indicated that the upper-tropospheric trough in that region was deeper and farther west in the NEtrack subset. The trough to the east of Joaquin in the NE-track subset was the only synoptic-scale feature with near-zero height errors at this time, suggesting its criticality to the location of the col. The subtle differences in these three synoptic-scale features near Joaquin were enough to support disparities in the upper-tropospheric col and, consequently, steering flow anomalies near Joaquin that significantly influenced its track. In particular, the eastward extent of the North American trough and the westward extent of the uppertropospheric trough dictated the longitude of the col (see Fig. 7). The North Atlantic ridge appeared to be less important to the location of the col at this time. Other studies similarly found that lower geopotential heights to the north and east of Joaquin were associated with a northeast track (Nystrom et al. 2018; Torn et al. 2018; Miller and Zhang 2019).

At 1200 UTC 3 October 2015, 500-hPa geopotential height errors in both subsets continued to describe a deeper trough over North America, a stronger ridge to the northeast of Joaquin, and a stronger ridge to the south of Joaquin (Figs. 8b,d). However, critical differences in the North American trough emerged between the two subsets at this time. For one, the trough in the NW-track subset was 1 gpdm deeper than in the NEtrack subset. In addition, although the center of the North American trough was similar in the two subsets, a region of negative height errors extended southeast of the trough center to $30^{\circ} \mathrm{N}, 67^{\circ} \mathrm{W}$ in the NE-track subset. This extension of negative height errors into the central North Atlantic was evidence of a shortwave trough that was also apparent in the upper-tropospheric steering flow (see Fig. 6b). Conversely, positive height errors in the NW-track subset indicated a stronger ridge that was positioned farther west, leading to amplified southerly steering flow to its west. Torn et al. (2018) also noted the importance of the North Atlantic ridge to the amplification of southerly steering flow near Joaquin. Furthermore, the NW-track subset showed no evidence of the shortwave trough in the steering flow or height fields (see Fig. 6d). Overall, the NE-track subset was more comparable with GFSA than the NW-track subset at this time. Root-mean-square errors for $500-\mathrm{hPa}$ geopotential height, calculated for the fields shown in Figs. $8 \mathrm{~b}$ and $8 \mathrm{~d}$, were more than $30 \%$ higher for the NW-track subset composite $\left(4.78 \times 10^{8} \mathrm{~m}^{2}\right)$ than the NE-track subset composite $\left(3.65 \times 10^{8} \mathrm{~m}^{2}\right)$. The col location and the evolution of nearby synoptic-scale features were critical factors in determining whether Joaquin would be steered toward or away from the United States in each HBE member.

To evaluate differences between the NE-track subset and the NW-track subset that were difficult to observe in composites, the environments from one member in each group were compared. Both members were chosen from J092912 forecasts to avoid discrepancies related to the model initialization time. The NE-track member (i.e., A08 in Fig. 4b) and NW-track member (i.e., A01 in Fig. 4b) were chosen based on the zonal position at a lead time of $72 \mathrm{~h}$, with the former being the most eastward member and the latter being the most westward 


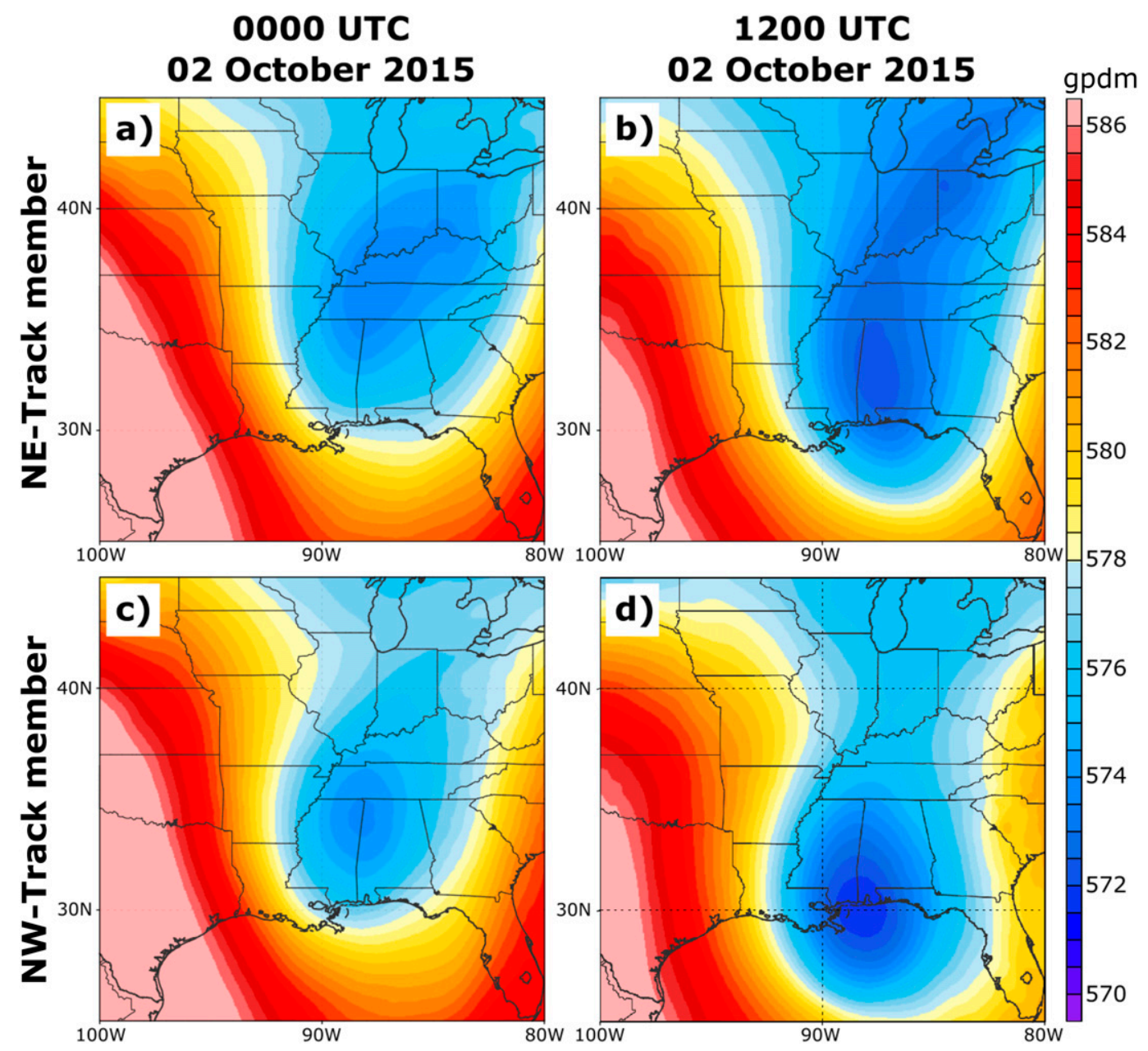

FIG. 10. NE-track member 500-hPa geopotential heights (gpdm) at (a) 0000 UTC 2 Oct 2015 (60 h into the J092912 forecast) and (b) 1200 UTC 2 Oct 2015 ( 72 h into the J092912 forecast). (c),(d) As in (a) and (b), but for NW-track member 500-hPa geopotential heights.

member. At the initial time, the NE-track member had negative 500-hPa geopotential height errors to the east of Joaquin and positive errors to the north of Joaquin (Fig. 9a). Conversely, the NW-track member had negative 500-hPa geopotential height errors to the south of Joaquin and positive errors to the north of Joaquin at the initial time (Fig. 9b). The NE-track member had lower geopotential heights than the NW-track member to the east of Joaquin, and geopotential height errors to the north of Joaquin were greater for the NW-track member than for the NE-track member. The growth of these initial height errors contributed to differences in the evolution of the synoptic-scale pattern near Joaquin at 0000 UTC 2 October 2015 (see Figs. 8a,c). Similarly, Nystrom et al. (2018) found that lower geopotential heights at the model initialization time to the east of Joaquin were associated with track forecasts to the northeast.
Although track forecasts for Joaquin were sensitive to the North Atlantic ridge and the trough to its east, subtle differences to the trough over North America proved to be vital to the evolution of steering flow near Joaquin. Geopotential heights at $500 \mathrm{hPa}$ revealed key differences in the trough structure between the NE-track member and the NW-track member (Fig. 10). In particular, the trough in the NE-track member remained embedded in the midlatitude westerly flow at 1200 UTC 2 October 2015, resulting in a progressive pattern that steered Joaquin out to sea (Figs. 10a,b). Conversely, the trough in the NW-track member appeared to be cutting off from the midlatitude westerlies, resulting in an amplified pattern with enhanced meridional flow ahead of the trough that steered Joaquin toward the United States (Figs. 10c,d). The main driver of these differences was the amplitude and location of the ridge to the north of Joaquin (see Figs. 8a,c). In the NE-track member, this 


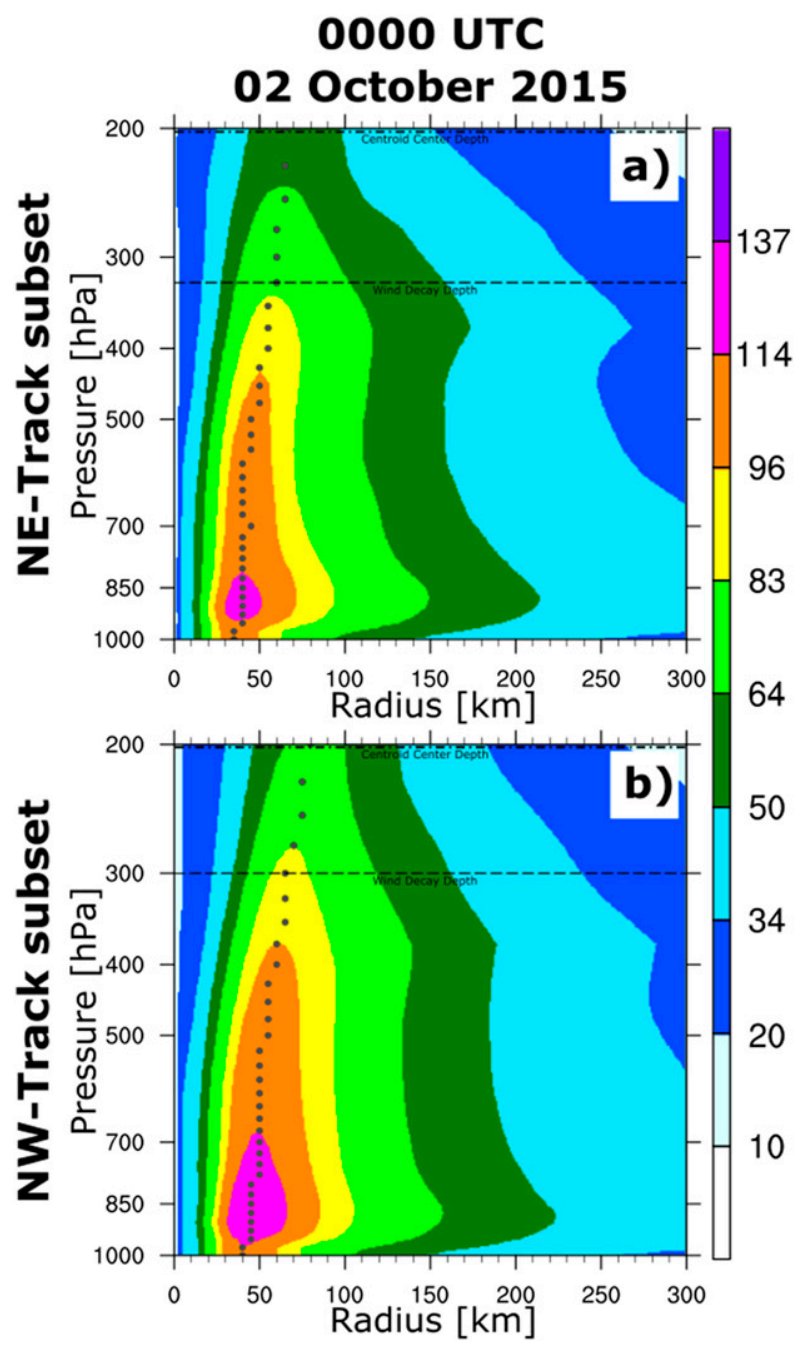

FIG. 11. Azimuthally averaged horizontal wind (kt) composites shown as a function of pressure and radius from TC center at each level, for (a) the NE-track subset at 0000 UTC 2 Oct 2015 and (b) as in (a), but for the NW-track subset. The radial location of the maximum horizontal wind is marked at each level (gray circle). The wind decay vortex depth (dashed line) and the centroid center vortex depth (dash-dot line) are labeled.

ridge was weaker and farther east, allowing the North American trough to progress faster to the east and contributing to a more zonal flow pattern. In the NW-track member, this ridge was stronger and farther west, acting to block progression of the North American trough and contributing to a relatively amplified flow pattern. As shown in Fig. 9, the amplitude of the ridge to the north of Joaquin appeared to be closely linked to initial geopotential height errors in the same region.

\section{c. Impact of the TC vortex structure}

Differences in the TC vortex were scrutinized for potential impacts on track forecast uncertainty for
Joaquin. At 0000 UTC 2 October 2015, the vortex structure had evolved very similarly for both the NE-track and NW-track subsets (Fig. 11). The NWtrack subset composite vortex had slightly stronger intensity than the NE-track subset composite (132 vs $121 \mathrm{kt}$ ). The vortex depth (see section $2 \mathrm{c}$ ) was the same for the centroid center definition (200 and $200 \mathrm{hPa}$, respectively) and only slightly different for the wind decay definition ( 300 and $325 \mathrm{hPa}$, respectively). The evolution of the vortex at other valid times was also very similar between these two groups (not shown), indicating that vortex variations were not an important factor in Joaquin track forecasts, and, more broadly, track uncertainty.

The initial TC vortex structure was also compared for the two individual HBE2 members (see section 3b). In general, the initial vortex structures in the NE-track member and the NW-track member were very similar, emphasizing the overall importance of the environment in driving track forecast differences among ensemble members (Figs. 12a,c). The initial vortex depth and radius of maximum winds in both members were comparable despite a slightly stronger initial maximum wind in the NE-track member (56 vs $51 \mathrm{kt}$ ). Vortex depth was identical between the two members, with the centroid center depth up to $225 \mathrm{hPa}$ and the wind decay depth up to $450 \mathrm{hPa}$. In both members, the initial vortex was tilted to the northeast between the surface and $250 \mathrm{hPa}$ (Figs. 12b,d). In the NE-track member, the vortex was more aligned below $\sim 450 \mathrm{hPa}$, but was also more tilted above $450 \mathrm{hPa}$. It is suggestive that subtle vortex structure differences at the initial time had little impact on Joaquin track forecasts since the vortex looked so similar later in the forecast.

\section{d. Impact of the initial TC vortex location}

Early in Joaquin's life cycle, its surface center moved sporadically beneath a strong midtropospheric center as the entire system drifted southwestward, leading to discrepancies between TCVitals and BEST. In fact, the surface center location in TCVitals was nearly $20 \mathrm{~km}$ north-northwest of the BEST location, translating to a difference of several grid points in the $3-\mathrm{km}$ inner domain configured in HBE. The uncertainty of the initial vortex location could have played a role in the resulting track spread for Joaquin forecasts.

A series of experiments tested the importance of the initial TC location to track forecast uncertainty. The goal of these experiments was to test if Joaquin could be artificially moved to the other side of the upper-tropospheric col, which was determined to be a dominant factor in Joaquin track forecast uncertainty (see section 3b). A new method called the 


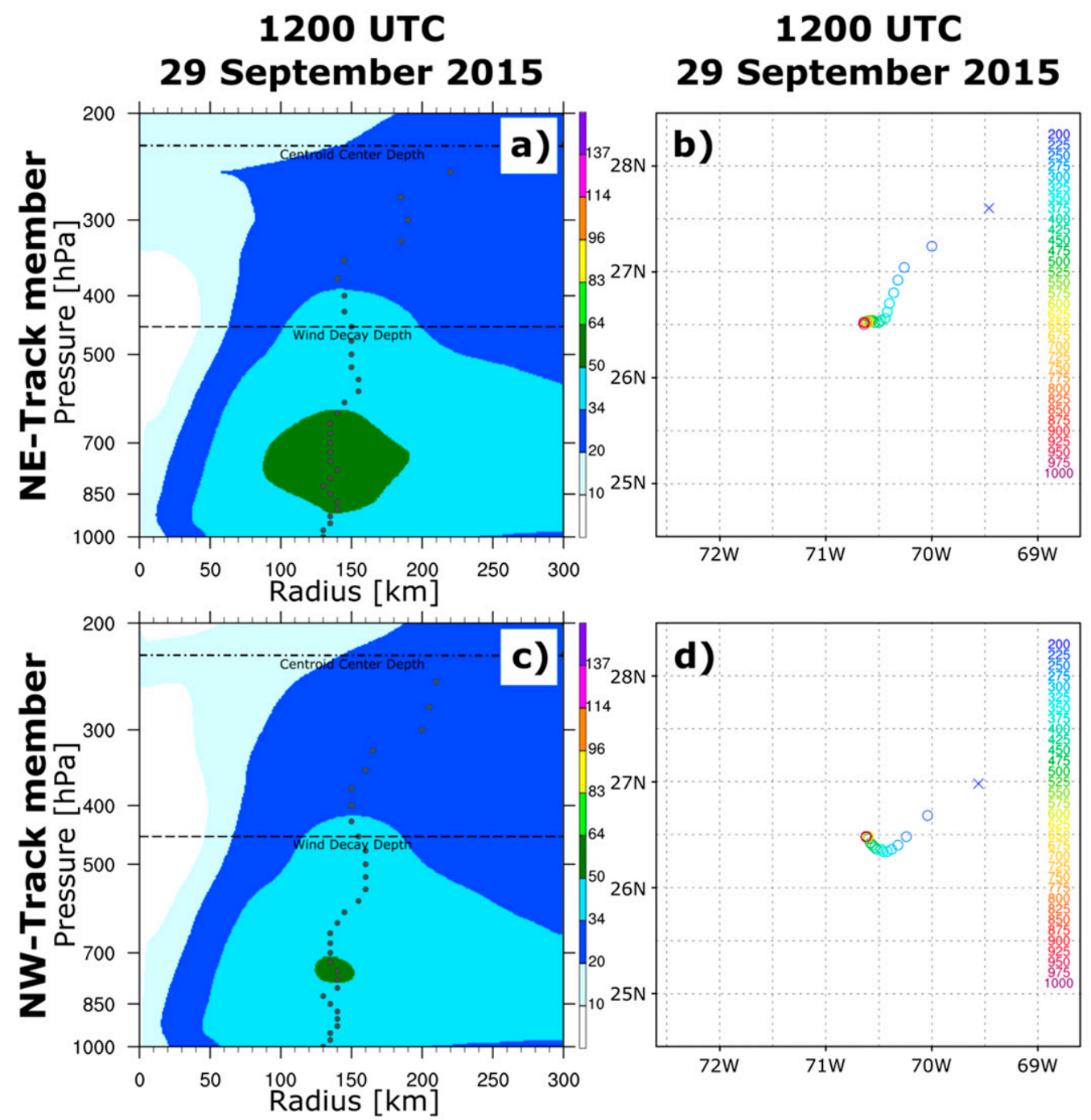

FIG. 12. (a) As in Fig. 11, but at the initial time of the J092912 forecast for the NE-track member, (b) corresponding geopotential height centroid center locations at each pressure level (listed on the right side of the panel in $\mathrm{hPa}$ ) for the NE-track member, (c) as in (a), but for the NW-track member, and (d), as in (b), but for the NW-track member. In (b) and (d), centers that are part of the TC vortex are marked by an " $\mathrm{O}$ " and those that are not part of the TC vortex are marked by an "X."

initial-location-varying (ILV) technique was developed to test the importance of the initial vortex location and was applied to HBE experiments. The ILV technique artificially places a TC center at 25 different locations based on the radius of maximum wind speed $(R)$ provided by TCVitals. Radius $R$ provides an objective measure of position uncertainty, with larger values typically indicating a less organized TC. It should be noted that $R$ has its own uncertainty, a topic that is beyond the scope of this study and worth further investigation in the future. Initial TC locations were placed at radii of $2 R, R, 0.5 R, 0.25 R$, and zero relative to the TC center (Fig. 13). At $0.25 R$ and $0.5 R$, initial
TC locations were placed at each cardinal direction. At $R$ and $2 R$, initial TC locations were placed at each cardinal direction and each intercardinal direction. For the $\mathrm{J} 092912$ forecast, $R$ was equal to $93 \mathrm{~km}$ (i.e., $0.8^{\circ}$ due to the precision of TCVitals). This value is consistent with the upper limit of BEST position uncertainty for tropical storms with satellite observations only (Landsea and Franklin 2013). We note that the ILV technique did not include any changes to TC structure and intensity in this study, although that is certainly a possible extension in future work.

The variability of the initial TC vortex location was not large enough to force Joaquin to the other side of 


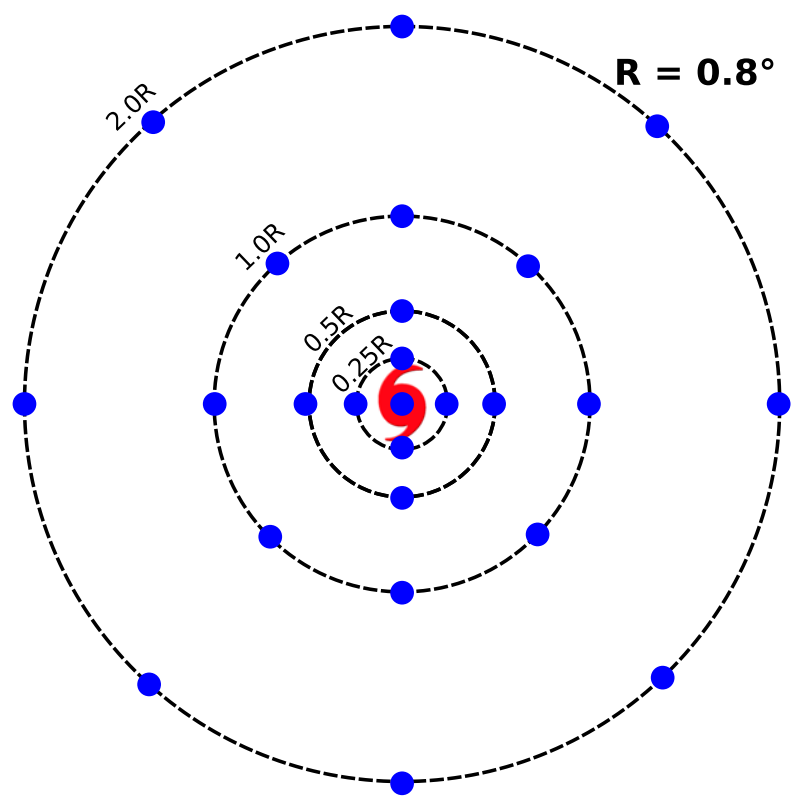

FIG. 13. Setup for the 25-member initial-location-varying perturbation technique. Here $R$ represents the radius $\left(^{\circ}\right)$ of the radius of maximum wind for Joaquin at 1200 UTC 29 Sep 2015.

the col. In HBE3, the ILV technique was applied using static GEFS initial conditions from the NE-track member (Table 1). HBE4 was configured the same as HBE3, except initial conditions from the NW-track member were used for all ensemble members. The GEFS members used as initial conditions for these two experiments (i.e., G08 for HBE3 and G01 for HBE4) had distinct track forecasts (see Fig. 3b). In HBE3 and HBE4, only the ILV technique provided perturbations to the ensemble members, with both stochastic physics perturbations and initial maximum intensity perturbations turned off. Despite varying its initial location by up to $1.6^{\circ}(2 R)$, every Joaquin track forecast clustered around the original track forecast for each respective member (Fig. 14). HBE3 had a mean track error of $325 \mathrm{~km}$ at $120 \mathrm{~h}$ with a standard deviation of only $36 \mathrm{~km}$, whereas HBE4 had a mean track error of $1637 \mathrm{~km}$ at $120 \mathrm{~h}$ with a standard deviation of only $51 \mathrm{~km}$ (Table 4). Once more, the environment was dominant in the motion of Joaquin for these two members, and even large deviations in the initial TC location were not enough to move Joaquin to the other side of the col axis. HBE3 was extended to include stochastic physics perturbations and initial maximum intensity perturbations (HBE5; Table 1). The addition of these perturbations did not produce any members that made landfall on the United States and failed to change track spread from HBE3 in any meaningful way (Fig. 15). For example, the mean track error for HBE5 at $120 \mathrm{~h}$ was $309 \mathrm{~km}$ with a standard deviation of $40 \mathrm{~km}$ (Table 4).

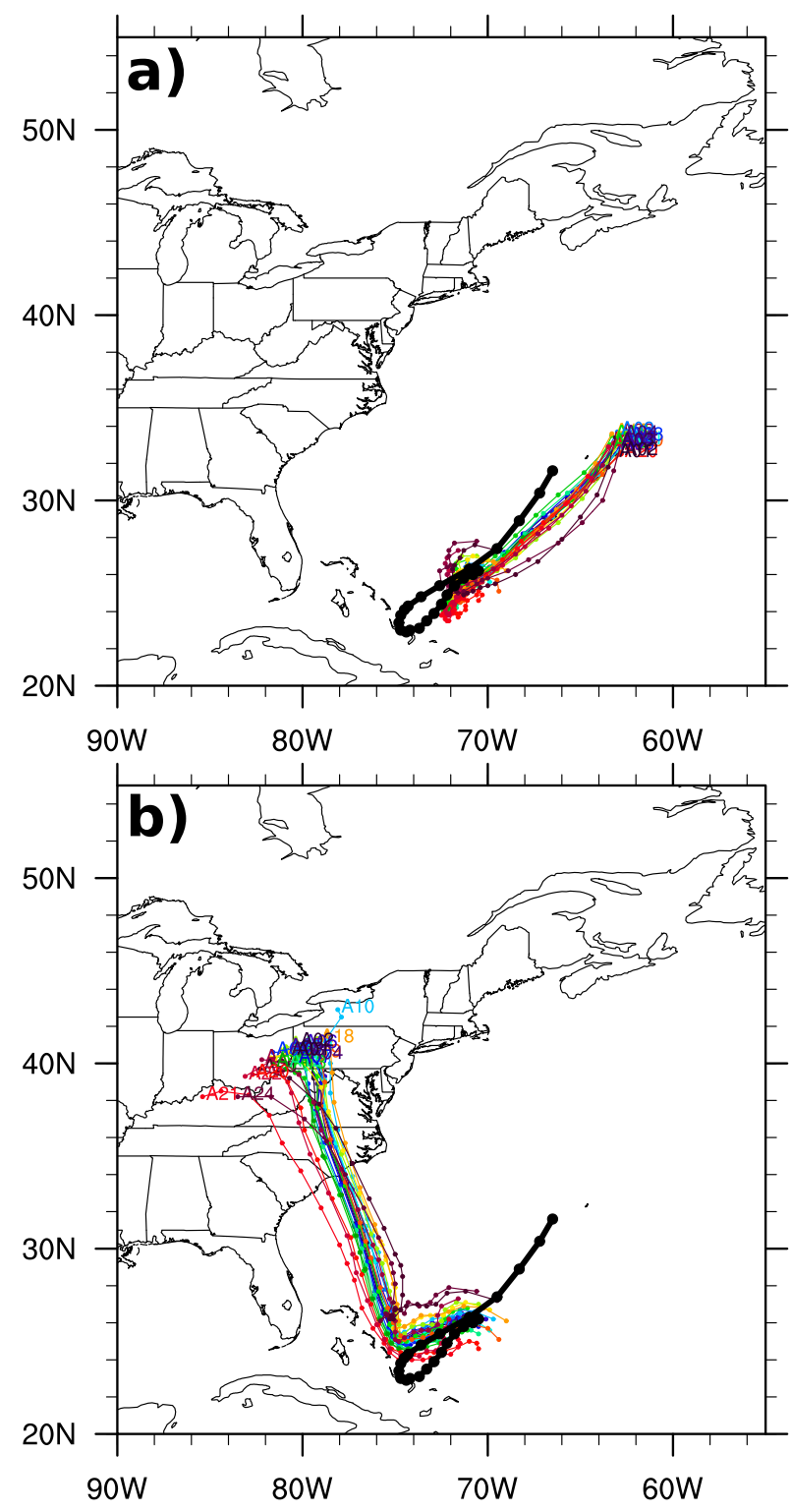

FIG. 14. Track forecasts initialized at 1200 UTC 29 Sep 2015 (J092912) for (a) HBE3 and (b) HBE4. Both ensemble forecasts include 25 members.

\section{Conclusions}

As Hurricane Joaquin (2015) meandered near the Bahamas from 1200 UTC 29 September 2015 to 0000 UTC 1 October 2015, operational numerical weather prediction models (e.g., GEFS) forecasted large track spread, including the potential for a major hurricane landfall in the United States. In reality, Joaquin propagated into the central North Atlantic without directly impacting the United States. In this study, a highresolution basin-scale HWRF EPS, called HBE, was developed to evaluate the relative importance of the 


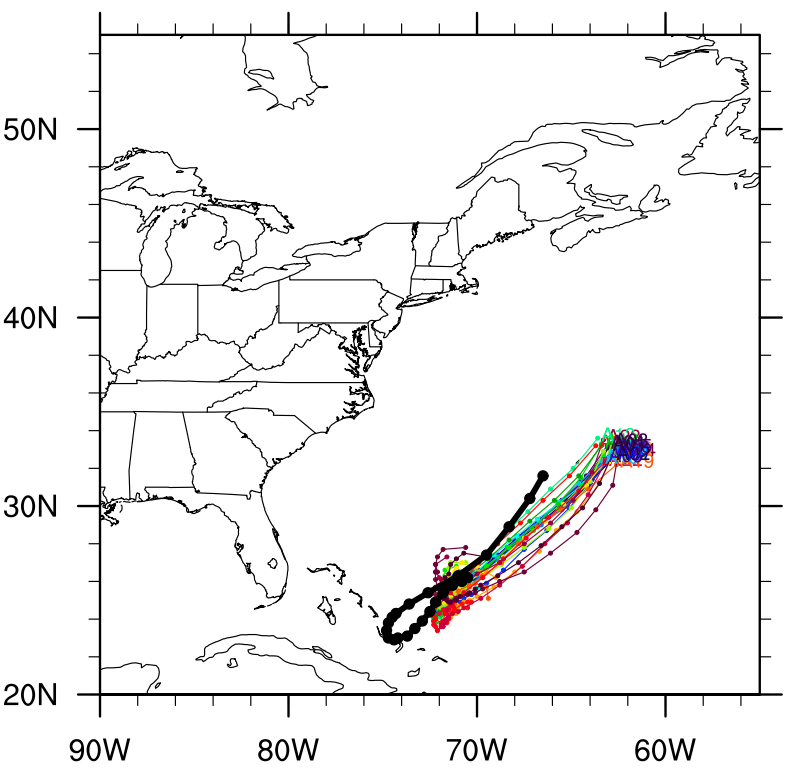

FIG. 15. As in Fig. 14, but for HBE5.

synoptic-scale environment (i.e., steering flow) and TC vortex (i.e., maximum intensity, structure, initial location) to Joaquin track forecast uncertainty. Here, we focused on Joaquin track errors at later lead times in model forecasts, when extreme impacts were possible for the U.S. East Coast. An important difference that distinguishes this current study from previous ones is that track forecasts to the northeast did not require the southwest loop at earlier lead times in HBE.

The evolution of the synoptic-scale environment was critical to the steering flow near Joaquin and, ultimately, its track (Fig. 16). Upper-tropospheric steering flow and the precise location of an upper-tropospheric col near the Bahamas dominated the trajectory of Joaquin. Three synoptic-scale features controlled the position of the col and the steering flow near Joaquin: a deep-tropospheric trough over North America, a deep-tropospheric ridge over the central North Atlantic, and an upper-tropospheric trough to the east of Joaquin. Although previous studies (Nystrom et al. 2018; Torn et al. 2018; Miller and Zhang 2019; Saunders et al. 2019) also reported the importance of the environment to Joaquin track forecasts, the connection of Joaquin track forecast uncertainty with the evolution of these large-scale features was a novel result of this study.

Differences in the initial conditions were important for the evolution of the synoptic-scale environment near Joaquin in HBE forecasts. In the NE-track subset, the North Atlantic ridge was weaker and the uppertropospheric trough to the east of Joaquin was deeper. At earlier lead times, variations in the upper-tropospheric col amongst HBE members were linked primarily to the

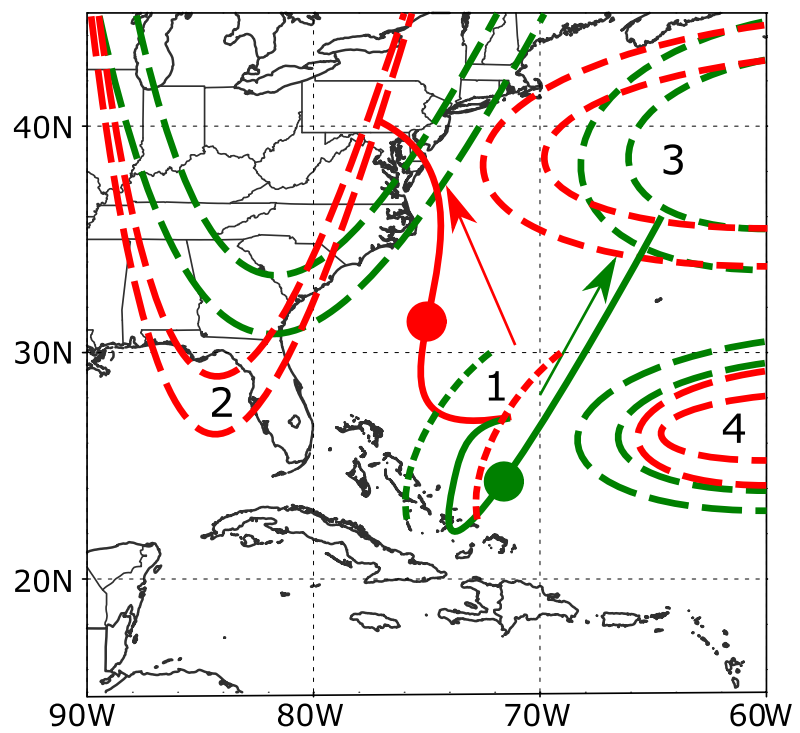

FIG. 16. Schematic comparing characteristics of the NE-track subset (green) vs the NW-track subset (red). The dominant synoptic-scale features are shown (dashed lines): 1) the $250-500-\mathrm{hPa}$ col axis, 2) the trough located over North America, 3) the ridge located to the northeast of Joaquin, and 4) the trough located to the east of Joaquin. The likeliest track associated with each subset is shown (solid lines) with the location of Joaquin (large circle). The arrows denote the upper-tropospheric steering flow in each subset.

North Atlantic ridge and the upper-tropospheric trough. NE-track members were associated with a weaker ridge and a deeper trough. Consequently, Joaquin was embedded in weak steering flow associated with the col for all NE-track members, while Joaquin was embedded in the southerly flow to the west of the col for all NW-track members (see Fig. 7). At later lead times, the North American trough and the North Atlantic ridge were the dominant synoptic-scale features that controlled the steering flow near Joaquin. In the NE-track subset, the North American trough and North Atlantic ridge were associated with a more progressive pattern, resulting in weaker flow between them that steered Joaquin to the northeast.

TC vortex perturbations (i.e., initial maximum intensity, ILV technique) unexpectedly had no significant impacts on Joaquin track uncertainty in HBE forecasts. In fact, the TC vortex, including maximum intensity, depth, and tilt, was similar for most HBE members. This result contends with the findings of Miller and Zhang (2019), who asserted that a shallower vortex led to large track errors at early lead times. The ILV technique reinforced the dominance of the synoptic-scale environment to Joaquin track forecast uncertainty. Even large deviations of the initial TC vortex location in the same environment did not significantly change track errors at later lead times. We want to emphasize that the ILV 
technique developed in this study can be applied to represent the uncertainty of TC surface center locations in any EPS.

This experimental basin-scale HWRF ensemble prediction system has broader applications, such as observing system experiments (OSEs), observing system simulation experiments (OSSEs), and data assimilation advancements. These applications can quantify the impact of additional or improved observations on TC forecasts. This ensemble approach developed in HBE can also be applied to the next generation hurricane analysis and forecast system.

Acknowledgments. The authors acknowledge funding from NOAA's HFIP that supported this work. We thank EMC, who helped develop HWRF-B and HWRF-EPS, and DTC, who maintain the community HWRF code. We also thank our colleagues Drs. Robert Rogers, Sim Aberson, and Andrew Hazelton for reviewing the manuscript, and the entire HRD modeling team for helpful discussions that strengthened the manuscript. We appreciate the comments from three anonymous reviewers, who helped improve this manuscript. GFSA data are publicly available in GRIdded Binary 2 (GRIB2) format at the NCEP NOMADS data server (http://nomads.ncep.noaa.gov/). BEST data are publicly available in Automated Tropical Cyclone Format (ATCF) text format is publicly available on the NHC data server (ftp://ftp.nhc.noaa.gov/atcf/). HWRF-B EPS forecast data are stored in GRIB2 and ATCF formats on NOAA supercomputers and are available upon request. All data from additional analyses required to draw our conclusions have been provided in graphical form. The raw data from these analyses are stored on NOAA supercomputers and are available upon request.

\section{REFERENCES}

Alaka, G. J. J., X. Zhang, S. G. Gopalakrishnan, S. B. Goldenberg, and F. D. J. Marks, 2017: Performance of basin-scale HWRF tropical cyclone track forecasts. Wea. Forecasting, 32, 12531271, https://doi.org/10.1175/WAF-D-16-0150.1.

Atlas, R., V. Tallapragada, and S. G. Gopalakrishnan, 2015: Advances in tropical cyclone intensity forecasts. Mar. Technol. J., 49, 149-160, https://doi.org/10.4031/MTSJ.49.6.2.

Bao, J.-W., S. G. Gopalakrishnan, S. A. Michelson, F. D. J. Marks, and M. T. Montgomery, 2012: Impact of physics representations in the HWRFX on simulated hurricane structure and pressure-wind relationships. Mon. Wea. Rev., 140, 3278-3299, https://doi.org/10.1175/MWR-D-11-00332.1.

Berg, R. J., 2016: Hurricane Joaquin (AL112015). National Hurricane Center Tropical Cyclone Rep., 36 pp., https://www.nhc.noaa.gov/ data/tcr/AL112015_Joaquin.pdf.

Biswas, M. K., and Coauthors, 2016: Hurricane Weather Research and Forecasting (HWRF) Model: 2016 scientific documentation. Developmental Testbed Center Doc., 95 pp.,
https://dtcenter.org/HurrWRF/users/docs/scientific_documents/ HWRFv3.8a_ScientificDoc.pdf.

Brand, S., C. A. Buenafe, and H. D. Hamilton, 1981: Comparison of tropical cyclone motion and environmental steering. Mon. Wea. Rev., 109, 908-909, https://doi.org/10.1175/1520-0493(1981) 109<0908:COTCMA > 2.0.CO;2.

Cangialosi, J. P., and J. L. Franklin, 2017: 2016 hurricane season. National Hurricane Center Forecast Verification Rep., 72 pp., http://www.nhc.noaa.gov/verification/pdfs/Verification_2016.pdf.

Carr, L. E. I., and R. L. Elsberry, 1990: Observational evidence for predictions of tropical cyclone propagation relative to environmental steering. J. Atmos. Sci., 47, 542-546, https://doi.org/ 10.1175/1520-0469(1990)047<0542:OEFPOT>2.0.CO;2.

Chan, J. C. L., 2005: The physics of tropical cyclone motion. Annu. Rev. Fluid Mech., 37, 99-128, https://doi.org/10.1146/ annurev.fluid.37.061903.175702.

— rounding flow relationships. Mon. Wea. Rev., 110, 1354-1374, https://doi.org/10.1175/1520-0493(1982)110<1354:TCMASF $>$ 2.0.CO;2.

Cheung, K. K. W., 2001: Ensemble forecasting of tropical cyclone motion: Comparison between regional bred modes and random perturbations. Meteor. Atmos. Phys., 78, 23-34, https:// doi.org/10.1007/s007030170003.

, and J. C. L. Chan, 1999a: Ensemble forecasting of tropical cyclone motion using a barotropic model. Part I: Perturbations of the environment. Mon. Wea. Rev., 127, 1229-1243, https://doi.org/ 10.1175/1520-0493(1999)127<1229:EFOTCM > 2.0.CO;2.

$\ldots$, and _ 1999b: Ensemble forecasting of tropical cyclone motion using a barotropic model. Part II: Perturbations of the vortex. Mon. Wea. Rev., 127, 2617-2640, https://doi.org/ 10.1175/1520-0493(1999)127<2617:EFOTCM>2.0.CO;2.

Corbosiero, K. L., and J. Molinari, 2002: The effects of vertical wind shear on the distribution of convection in tropical cyclones. Mon. Wea. Rev., 130, 2110-2123, https://doi.org/10.1175/ 1520-0493(2002)130<2110:TEOVWS $>2.0$.CO;2.

$\longrightarrow$, and -2003 : The relationship between storm motion, vertical wind shear, and convective asymmetries in tropical cyclones. J. Atmos. Sci., 60, 366-376, https://doi.org/10.1175/ 1520-0469(2003)060<0366:TRBSMV >2.0.CO;2.

Dengler, K., and M. J. Reeder, 1997: The effects of convection and baroclinicity on the motion of tropical-cyclone-like vortices. Quart. J. Roy. Meteor. Soc., 123, 699-725, https://doi.org/ 10.1002/qj.49712353909.

Durran, D. R., and M. Gingrich, 2014: Atmospheric predictability: Why butterflies are not of practical importance. J. Atmos. Sci. 71, 2476-2488, https://doi.org/10.1175/JAS-D-14-0007.1.

Finocchio, P. M., S. J. Majumdar, D. S. Nolan, and M. Iskandarani, 2016: Idealized tropical cyclone responses to the height and depth of environmental vertical wind shear. Mon. Wea. Rev., 144, 2155-2175, https://doi.org/10.1175/MWR-D-15-0320.1.

Flatau, M., W. H. Schubert, and D. E. Stevens, 1994: The role of baroclinic processes in tropical cyclone motion: The influence of vertical tilt. J. Atmos. Sci., 51, 2589-2601, https://doi.org/ 10.1175/1520-0469(1994)051<2589:TROBPI > 2.0.CO;2.

George, J. E., and W. M. Gray, 1976: Tropical cyclone motion and surrounding parameter relationships. J. Appl. Meteor., 15, 1252-1264, https://doi.org/10.1175/1520-0450(1976)015<1252: TCMASP $>2.0$. CO;2.

Gopalakrishnan, S. G., F. D. J. Marks, X. Zhang, J.-W. Bao, K.-S. Yeh, and R. Atlas, 2011: The experimental HWRF system: A study on the influence of horizontal resolution on the structure and intensity changes in tropical cyclones using an idealized 
framework. Mon. Wea. Rev., 139, 1762-1784, https://doi.org/ 10.1175/2010MWR3535.1.

—, S. B. Goldenberg, T. S. Quirino, X. Zhang, F. D. J. Marks, K.-S. Yeh, R. Atlas, and V. Tallapragada, 2012: Toward improving high-resolution numerical hurricane forecasting: Influence of model horizontal grid resolution, initialization, and physics. Wea. Forecasting, 27, 647-666, https://doi.org/10.1175/ WAF-D-11-00055.1.

—, F. D. J. Marks, J. A. Zhang, X. Zhang, J.-W. Bao, and V. Tallapragada, 2013: A study of the impacts of vertical diffusion on the structure and intensity of the tropical cyclones using the high resolution HWRF system. J. Atmos. Sci., 70, 524-541, https://doi.org/10.1175/JAS-D-11-0340.1.

— , and Coauthors, 2018: 2017 HFIP R\&D activities summary: Recent results and operational implementation. NOAA HFIP Tech. Rep. HFIP2018-1, 34 pp., http://www.hfip.org/documents/ HFIP_AnnualReport_FY2017.pdf.

Grams, C. M., S. C. Jones, and C. A. Davis, 2013: The impact of Typhoon Jangmi (2008) on the midlatitude flow. Part II: Downstream evolution. Quart. J. Roy. Meteor. Soc., 139, 2165 2180, https://doi.org/10.1002/qj.2119.

Hazelton, A. T., L. Harris, and S.-J. Lin, 2018: Evaluation of tropical cyclone structure forecasts in a high-resolution version of the multiscale GFDL fvGFS model. Wea. Forecasting, 33, 419-442, https://doi.org/10.1175/WAF-D-17-0140.1.

Holland, G. J., 1983: Tropical cyclone motion: Environmental interaction plus a beta effect. J. Atmos. Sci., 40, 328-342, https:// doi.org/10.1175/1520-0469(1983)040<0328:TCMEIP>2.0.CO;2.

Hou, D., Z. Toth, and Y. Zhu, 2006: A stochastic parameterization scheme within NCEP global ensemble forecast system. 18th Conf. on Probability and Statistics in the Atmospheric Sciences, Atlanta, GA, Amer. Meteor. Soc., 4.5, https://ams.confex.com/ ams/Annual2006/techprogram/paper_101401.htm.

Kasahara, A., and G. W. Platzman, 1963: Interaction of a hurricane with the steering flow and its effect upon the hurricane trajectory Tellus, 15, 321-335, https://doi.org/10.3402/tellusa.v15i4.8863.

Krishnamurti, T. N., R. Correa-Torres, G. Rohaly, D. Oosterhof, and N. Surgi, 1997: Physical initialization and hurricane ensemble forecasts. Wea. Forecasting, 12, 503-514, https://doi.org/10.1175/ 1520-0434(1997)012<0503:PIAHEF > 2.0.CO;2.

- C. M. Kishtawal, Z. Zhang, T. LaRow, D. Bachiochi, E. Williford, S. Gadgil, and S. Surendran, 2000: Multimodel ensemble forecasts for weather and seasonal climate. J. Climate, $\mathbf{1 3}$, 4196-4216, https://doi.org/10.1175/1520-0442(2000)013<4196: MEFFWA $>2.0 . \mathrm{CO} ; 2$.

Kurihara, Y., M. A. Bender, and R. J. Ross, 1993: An initialization scheme of hurricane models by vortex specification. Mon. Wea. Rev., 121, 2030-2045, https://doi.org/10.1175/1520-0493(1993) $121<2030$ :AISOHM $>2.0$.CO;2.

Landsea, C. W., and J. L. Franklin, 2013: Atlantic hurricane database uncertainty and presentation of a new database format. Mon. Wea. Rev., 141, 3576-3592, https://doi.org/10.1175/ MWR-D-12-00254.1.

Majumdar, S. J., and P. M. Finocchio, 2010: On the ability of global ensemble prediction systems to predict tropical cyclone track probabilities. Wea. Forecasting, 25, 659-680, https://doi.org/ 10.1175/2009WAF2222327.1.

Marks, D. G., 1992: The beta and advection model for hurricane track forecasting. NOAA Tech. Memo. NWS NMC 70, 89 pp., https://repository.library.noaa.gov/view/noaa/7184.

Miller, B. I., 1958: The use of mean layer winds as hurricane steering mechanism. National Hurricane Research Project Rep. 18, 24 pp., http://www.aoml.noaa.gov/general/lib/TM/NHRP_18_1958.pdf.
Miller, W., and D.-L. Zhang, 2019: Understanding the unusual looping track of Hurricane Joaquin (2015) and its forecast errors. Mon. Wea. Rev., 147, 2231-2259, https://doi.org/10.1175/ MWR-D-18-0331.1.

National Transportation Safety Board, 2017: Sinking of US Cargo Vessel SS El Faro. Accident Rep. NTSB/MAR-17-01, 282 pp., https://www.ntsb.gov/investigations/AccidentReports/Reports/ MAR1701.pdf.

Nystrom, R. G., F. Zhang, E. B. Munsell, S. A. Braun, J. A. Sippel, Y. Weng, and K. Emanuel, 2018: Predictability and dynamics of Hurricane Joaquin (2015) explored through convectionpermitting ensemble sensitivity experiments. J. Atmos. Sci., 75, 401-424, https://doi.org/10.1175/JAS-D-17-0137.1.

Onderlinde, M. J., and D. S. Nolan, 2016: Tropical cyclone-relative environmental helicity and the pathways to intensification in shear. J. Atmos. Sci., 73, 869-890, https://doi.org/10.1175/JASD-15-0261.1.

Pan, H.-L., and W.-S. Wu, 1995: Implementing a mass flux convection parameterization package for the NMC mediumrange forecast model. NCEP Office Note 409, 43 pp., https:// repository.library.noaa.gov/view/noaa/11429.

Rappaport, E. N., and Coauthors, 2009: Advances and challenges at the National Hurricane Center. Wea. Forecasting, 24, 395419, https://doi.org/10.1175/2008WAF2222128.1.

Riehl, H., and R. J. Shafer, 1944: The recurvature of tropical storms. J. Meteor., 1, 42-54, https://doi.org/10.1175/1520-0469(1944) $001<0001$ :TROTS $>2.0 . \mathrm{CO} ; 2$.

Riemer, M., and S. C. Jones, 2014: Interaction of a tropical cyclone with a high-amplitude, midlatitude wave pattern: Waviness analysis, trough deformation and track bifurcation. Quart. J. Roy. Meteor. Soc., 140, 1362-1376, https://doi.org/10.1002/ qj.2221.

Ryglicki, D. R., J. D. Doyle, Y. Jin, D. Hodyss, and J. H. Cossuth, 2018: The unexpected rapid intensification of tropical cyclones in moderate vertical wind shear. Part II: Vortex tilt. Mon. Wea. Rev., 146, 3801-3825, https://doi.org/10.1175/MWR-D-18-0021.1.

Saunders, P., Y. Yu, and Z. Pu, 2019: Sensitivity of numerical simulations of Hurricane Joaquin (2015) to cumulus parameterization schemes: Implications for processes controlling a hairpin turn in the track. J. Meteor. Soc. Japan II, 97, 577-595, https://doi.org/10.2151/jmsj.2019-030.

Scheck, L., S. C. Jones, and M. Juckes, 2011: The resonant interaction of a tropical cyclone and a tropopause front in a barotropic model. Part II: Frontal waves. J. Atmos. Sci., 68, 420-429, https://doi.org/10.1175/2010JAS3483.1.

Simpson, R. H., and H. Saffir, 1974: The hurricane disasterpotential scale. Weatherwise, 27, 169-186, https://doi.org/ 10.1080/00431672.1974.9931702.

Sirutis, J. J., and K. Miyakoda, 1990: Subgrid scale physics in 1-month forecasts. Part I: Experiment with four parameterization packages. Mon. Wea. Rev., 118, 1043-1064, https://doi.org/10.1175/ 1520-0493(1990)118<1043:SSPIMF>2.0.CO;2.

Stern, D. P., and D. S. Nolan, 2011: On the vertical decay rate of the maximum tangential winds in tropical cyclones. J. Atmos. Sci., 68, 2073-2094, https://doi.org/10.1175/2011JAS3682.1.

Tallapragada, V., C. Kieu, Y. Kwon, S. Trahan, Q. Liu, Z. Zhang, and I.-H. Kwon, 2014: Evaluation of storm structure from the operational HWRF model during 2012 implementation. Mon. Wea. Rev., 142, 4308-4325, https://doi.org/10.1175/ MWR-D-13-00010.1.

Torn, R. D., and C. A. Davis, 2012: The influence of shallow convection on tropical cyclone track forecasts. Mon. Wea. Rev., 140, 2188-2197, https://doi.org/10.1175/MWR-D-11-00246.1. 
, and C. Snyder, 2012: Uncertainty of tropical cyclone best-track information. Wea. Forecasting, 27, 715-729, https://doi.org/ 10.1175/WAF-D-11-00085.1.

— T. T. Elless, P. P. Papin, and C. A. Davis, 2018: Tropical cyclone track sensitivity in deformation steering flow. Mon. Wea. Rev., 146, 3183-3201, https://doi.org/10.1175/MWR-D-18-0153.1.

Troen, I. B., and L. Mahrt, 1986: A simple model of the atmospheric boundary layer; sensitivity to surface evaporation. Bound.-Layer Meteor., 37, 129-148, https://doi.org/10.1007/BF00122760.

Velden, C. S., and L. M. Leslie, 1991: The basic relationship between tropical cyclone intensity and the depth of the environmental steering layer in the Australian region. Wea. Forecasting, 6, 244-253, https://doi.org/10.1175/1520-0434(1991) 006 <0244:TBRBTC $>2.0$. CO;2.

Warner, T. T., R. A. Peterson, and R. E. Treadon, 1997: A tutorial on lateral boundary conditions as a basic and potentially serious limitation to regional numerical weather prediction. Bull. Amer. Meteor. Soc., 78, 2599-2617, https://doi.org/10.1175/15200477(1997)078<2599:ATOLBC $>2.0$.CO;2.

Weber, H. C., 2003: Hurricane track prediction using a statistical ensemble of numerical models. Mon. Wea. Rev., 131, 749-770, https://doi.org/10.1175/1520-0493(2003)131<0749: HTPUAS $>2.0 . \mathrm{CO} ; 2$.

Wei, M., Z. Toth, R. Wobus, Y. Zhu, C. H. Bishop, and X. Wang, 2006: Ensemble transform Kalman filter-based ensemble perturbations in an operational global prediction system at NCEP. Tellus, $\mathbf{5 8 A}$, 28-44, https://doi.org/10.1111/j.1600-0870.2006.00159.x.

,,--- , and -2008 : Initial perturbations based on the ensemble transform (ET) technique in the NCEP global operational forecast system. Tellus, 60A, 62-79, https://doi.org/ 10.1111/j.1600-0870.2007.00273.x.

Wu, C.-C., and Y. Kurihara, 1996: A numerical study of the feedback mechanisms of hurricane-environment interaction on hurricane movement from the potential vorticity perspective.
J. Atmos. Sci., 53, 2264-2282, https://doi.org/10.1175/ 1520-0469(1996)053<2264:ANSOTF>2.0.CO;2.

Zhang, B., R. S. Lindzen, V. Tallapragada, F. Weng, Q. Liu, J. A. Sippel, Z. Ma, and M. A. Bender, 2016: Increasing vertical resolution in US models to improve track forecasts of Hurricane Joaquin with HWRF as an example. Proc. Natl. Acad. Sci. USA, 113, 11 765-11 769, https://doi.org/10.1073/pnas.1613800113.

Zhang, F., and D. Tao, 2013: Effects of vertical wind shear on the predictability of tropical cyclones. J. Atmos. Sci., 70, 975-983, https://doi.org/10.1175/JAS-D-12-0133.1.

Zhang, J. A., R. F. Rogers, D. S. Nolan, and F. D. J. Marks, 2011: On the characteristic height scales of the hurricane boundary layer. Mon. Wea. Rev., 139, 2523-2535, https://doi.org/10.1175/ MWR-D-10-05017.1.

Zhang, X., S. G. Gopalakrishnan, S. Trahan, T. S. Quirino, Q. Liu, Z. Zhang, G. J. J. Alaka, and V. Tallapragada, 2016: Representing multiple scales in the hurricane weather research and forecasting modeling system: Design of multiple sets of movable multilevel nesting and the basin-scale HWRF forecast application. Wea. Forecasting, 31, 2019-2034, https://doi.org/ 10.1175/WAF-D-16-0087.1.

Zhang, Z., 1997: Hurricane ensemble prediction using EOF-based perturbations. Ph.D. thesis, Florida State University, 174 pp. , and T. N. Krishnamurti, 1997: Ensemble forecasting of hurricane tracks. Bull. Amer. Meteor. Soc., 78, 2785-2795, https:// doi.org/10.1175/1520-0477(1997)078<2785:EFOHT>2.0.CO;2. , and _ 1999: A perturbation method for hurricane ensemble predictions. Mon. Wea. Rev., 127, 447-469, https://doi.org/ 10.1175/1520-0493(1999)127<0447:APMFHE > 2.0.CO;2.

__ , V. Tallapragada, C. Kieu, S. Trahan, and W. Wang, 2014: HWRF based ensemble prediction system using perturbations from GEFS and stochastic convective trigger function. Trop. Cyclone Res. Rev., 3, 145-161, https://doi.org/10.6057/ 2014TCRR03.02. 